\title{
UNIVERSITY OF HAWAI'I LIBRARY \\ THE PREDICTIVE ACCURACY OF SHORELINE CHANGE RATE \\ METHODS AND ALONGSHORE BEACH VARIATION \\ ON MAUI, HAWAI'I
}

\section{A THESIS SUBMITTED TO THE GRADUATE DIVISION OF THE UNIVERSITY OF HAWAI'I IN PARTIAL FULFILLMENT OF THE REQUIREMENTS FOR THE DEGREE OF \\ MASTER OF SCIENCE}

IN

GEOLOGY AND GEOPHYSICS

AUGUST 2005

\author{
By \\ Ayesha S. Genz \\ Thesis Committee: \\ Charles H. Fletcher, Chairperson \\ Robert A. Dunn \\ John J. Rooney \\ L. Neil Frazer
}




\section{ACKNOWLEDGEMENTS}

I would like to thank my advisor, Charles "Chip" Fletcher. He has been instrumental in the progress of my work - challenging me throughout my graduate career. Chip has also been very understanding when my family issues took a priority over school. I would also like to thank my other committee members: Rob Dunn, Neil Frazer and John Rooney for their valuable time and assistance. Without their help and input, this work would not have evolved into what it is now. I would also like to thank the members of the Coastal Geology Group for their technical help. I especially would like to thank Chris Conger for his suggestions during times of extreme frustration. I also would like to acknowledge fellow graduate student Seung-Sep Kim for his valuable assistance in programming in Matlab. Finally, I would like to acknowledge Dr. Michael Fenster for graciously providing me with the MDL executable program.

Funding for this study was provided by the University of Hawai'i Sea Grant College, the U.S. Geological Survey National Shoreline Assessment Project, Maui County, the State of Hawai I I Department of Land and Natural Resources, the Hawai'I Coastal Zone Management Program, and the NOAA Coastal Services Center.

My sincerest thanks go to my family, especially my husband Joe Genz. Joe's patience and understanding throughout my tenure at the school has been phenomenal. I am also extremely thankful for his edits of every version of the manuscript. I would also like to thank my parents and sister for their continual support and advice. Having gone through this herself, my sister was able to give me valuable insight within the research process. Last, but certainly not least, I would like to thank and acknowledge my 
grandfather, who instilled in his five daughters the importance of education. Without his influence, I would not be where I am today. 


\begin{abstract}
Beach erosion has direct consequences for Hawai'i's tourist-based economy, which depends largely on the attraction of beautiful sandy beaches. Within the last century, however, beaches on Oahu and Maui have been narrowed or completely lost, threatening tourism and construction development. In order for the counties and state of Hawai' $i$ to implement coastal regulations to prevent infrastructure damage, it is necessary to find a statistical methodology that accurately delineates annual erosion hazard rates specific to Hawai' $i$. We compare the following erosion rate methods: end point rate (EPR), average of rates (AOR), minimum description length (MDL), jackknifing (JK), ordinary least squares (OLS), reweighted least squares (RLS), weighted least squares (WLS), reweighted weighted least squares (RWLS), least absolute deviation (LAD), and weighted least absolute deviation (WLAD). To evaluate these statistical methods, this study determines the predictive accuracy of various calculated erosion rates, including the effects of a priori (storm) outliers, using (1) temporally truncated data to forecast and hindcast known shorelines, and (2) synthetic beach time series that contain noise. This study also introduces binning of adjacent transects to identify segments of a beach that have erosion rates that are indistinguishable. If major uncertainties of the shoreline methodology and storms are known, WLS, RWLS, and WLAD are better methods; if storms are not known, RWLS and WLAD are preferred. If both uncertainties and storms are not known, RLS and LAD are preferred; if storms are known, OLS, RLS, JK, and LAD are recommended. MDL and AOR produce the most variable results. Early $20^{\text {th }}$ century topographic surveys are valuable in change rate analyses. Binning adjacent
\end{abstract}


transects improves the signal-to-noise ratio by increasing the number of data points. Binning also reflects long-term sand transport within a beach system. 


\section{TABLE OF CONTENTS}

Acknowledgements ......................... iii

Abstract ............................. v

List of Tables . . . . . . . . . . . . . . . . . . . . viii

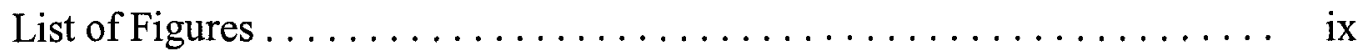

List of Abbreviations . . . . . . . . . . . .

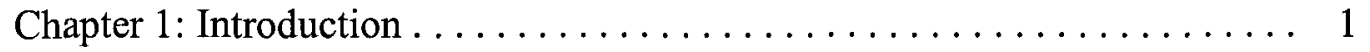

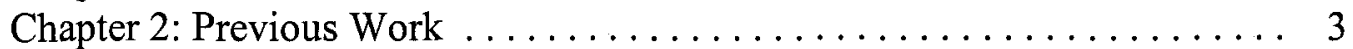

Chapter 3: Established Erosion Rate Methods .............. 5

Chapter 4: New Erosion Rate Methods . . . . . . . . . . . . . . . 10

Chapter 5: Hawaiian Data and Uncertainties .................. 14

Chapter 6: Methods . . . ............................ 16

Forecasting and Hindcasting (Cross-validation) $\ldots \ldots \ldots \ldots \ldots \ldots$

Syntethic Beach Time Series . . . . . . . . . . . . . . . . 17

Hawaiian Beaches and Binning of Shoreline Data . . . . . . . . . . 19

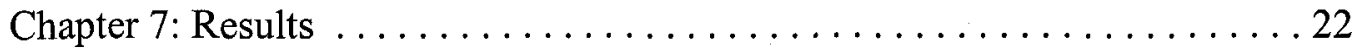

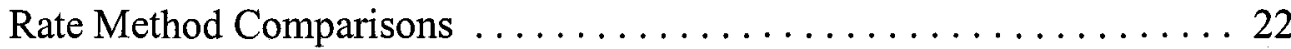

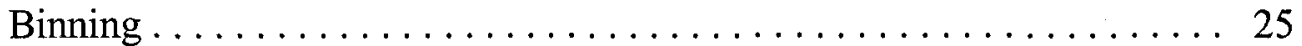

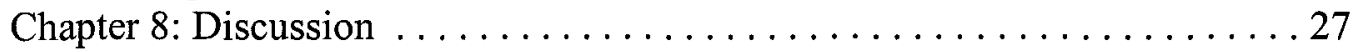

Comparison of Rate Methods . . . . . . . . . . . . . 27

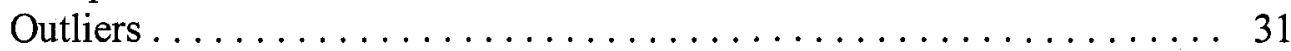

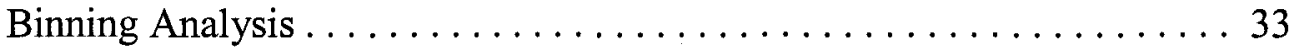

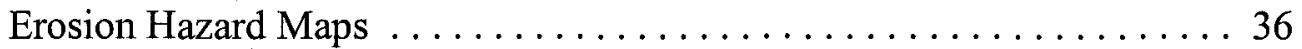

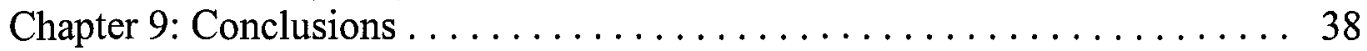

Appendix A: Tables . . . . . . . . . . . . . . . . . . . 39

Appendix B: Figures . . . . . . . . . . . . . . . . . . . . 50

Appendix C: Errors and Uncertainties $\ldots \ldots \ldots \ldots \ldots \ldots \ldots \ldots \ldots 6$

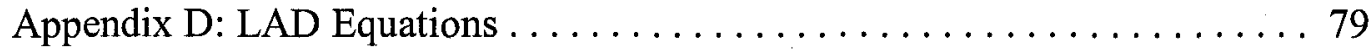

References ............................ 81 


\section{LIST OF TABLES}

Table

$\underline{\text { Page }}$

1. Abbreviations in Text ...................... 39

2. An Example of a Misfit Function for $\operatorname{LAD} \ldots \ldots \ldots \ldots \ldots \ldots$

3. Forecasts Free of Hardened Structures . . . . . . . . . . . . 41

4. Forecasts With Hardened Structures . . . . . . . . . . . . . . 42

5. Hindcasts Free of Hardened Structures . . . . . . . . . . . . . 43

6. Hindcasts With Hardened Structures . . . . . . . . . . . . . . . 44

7. Kolmogorov-Smirnov Results of Syntethic Analysis . . . . . . . . . 45

8. Binning Trends $\ldots \ldots \ldots \ldots \ldots \ldots \ldots \ldots \ldots \ldots \ldots$

9. Forecasts at Kanaha (North Shore) . . . . . . . . . . . 47

10. Forecasts at Kahului (North Shore) . . . . . . . . . . . . 48

11. Hindcast Uncertainties of Known and Predicted

Positions . . . . ...................... 49 


\section{LIST OF FIGURES}

$\underline{\text { Figure }}$

$\underline{\text { Page }}$

1. Published Shoreline Change Rate Methods .......... . . 50

2. New Shoreline Change Rate Methods ............. 51

3. Map of Maui ..................... 52

4. Window Spacing for Binning $\ldots \ldots \ldots \ldots \ldots \ldots$

5. Significant Window Groupings for Binning $\ldots \ldots \ldots \ldots 4$

6. T-test Results Within Each Window Size . . . . . . . . 55

7. Identification of Clusters of Transects $\ldots \ldots \ldots \ldots \ldots 6$

8. Cluster Shading on Specific Beach . . . . . . . . . . . . . 57

9. Predictions From a Transect in Kahului . . . . . . . . . . . 58

10. Histogram of Synthetic Time Series of Low Noise and No Storm . . . . . . . . . . . . . . . . . . 59

11. Histogram of Synthetic Time Series of More

Noise and No Storm . . . . . . . . . . . . . 60

12. Histogram of Synthetic Time Series of Low

Noise and Storm at Mid Point. . . . . . . . . . . . 61

13. Histogram of Synthetic Time Series of More

Noise and Storm at Mid Point. ............ 62

14. Histogram of Synthetic Time Series of Low

Noise and Storm at End Point. .............. 63

15. Histogram of Synthetic Time Series of More

Noise and Storm at End Point. . . . . . . . . . . 64

16. Binning of Kaanapali, Maui . . . . . . . . . . . . 65

17. Flow Chart for Creating Hazard Map . . . . . . . . . . 66

18. An Example of an Erosion Hazard Map . . . . . . . . . . 67 ix 


\section{LIST OF ABBREVIATIONS}

1. EPR

2. $\mathrm{AOR}$

3. MDL LOW

4. MDL ZERO

5. OLS

6. WLS

7. RLS

8. RWLS

9. JK

10. LAD

11. WLAD

12. EIP

13. $\sigma$

14. $\Sigma$
End Point Rate

Average of Rates

Minimum Description Length - Low Weight Line

Minimum Description Length - Zero Weight Line

Ordinary Least Squares

Weighted Least Squares

Reweighted Least Squares

Reweighted Weighted Least Squares

Jackknifing

Least Absolute Deviation

Weighted Least Absolute Deviation

Error In Prediction

Lower Case Sigma - signifies standard deviation

Upper Case Sigma - signifies summation 


\section{CHAPTER 1 \\ INTRODUCTION}

The coastal zone is one of the nation's greatest environmental and economic assets (Ocean Studies Board, 1999). In Hawai ' $i$, for example, over $60 \%$ of all jobs are related to tourism, which depends largely on the appeal of sandy beaches. Yet widespread beach erosion in the Hawaiian Islands threatens sand-dependent ecosystems and abutting coastal owners (Fletcher et al., 1997; Norcross-Nu'u and Abbott, 2005; Rooney et al., 2003).

Recognition of beach value led Maui County to approve and adopt the only sciencebased setback rules in Hawai ${ }^{i} i$ in October 2003. These rules are based on erosion rates that are calculated by the reweighted least squares (RLS, see Table 1) method, which identifies and removes outliers before modeling the shoreline change trend with a straight line (Fletcher et al., 2003; Rooney, 2002; Rooney et al., 2003). The slope of the line represents the erosion (positive slope) and accretion (negative slope) rate of the beach.

Although comparisons of different shoreline change rate methodologies have been conducted along the continental east coast of the U.S., extensive research does not exist for beaches in Hawai' $i$. Due to fundamental differences between Hawaiian beaches and those of the continental mainland (e.g., sediment composition, seasonal signal, and storm frequency and impact), there is a need for studies specific to Hawai' $i$. Additionally, previous studies have not comprehensively tested shoreline change rate methodologies.

Our goal is to compare published statistical shoreline change rate methods, including three statistical methods previously not used in calculating shoreline change rates. These comparisons are made using shoreline change data from the island of Maui. We first 
investigate the effects of a priori outliers (e.g., a devastating tsunami, hurricane or storm event) on predictions that are based on shoreline change rates. We then compare different shoreline change rate methods using synthetically derived data. Finally, we examine the binning of adjacent transects to find a well-constrained trend of the beach. 


\section{CHAPTER 2 \\ PREVIOUS WORK}

Most studies of shoreline changes have been done on continental beaches of the eastern U.S. We review these and other studies that determine the most appropriate method based on either a comparative approach or the prediction of known positions.

Dolan et al. (1991) compare long-term and short-term erosion rates with methods such as end-point rate (EPR), linear regression (hereafter ordinary least squares - OLS), jackknifing (JK), and average-of-rates (AOR). By plotting the rates from one method versus the rates of another method, they conclude that AOR is most variable, while OLS and JK share a high degree of similarity. They stress that the best method depends on the objective and the temporal variables of the research.

In discussing beach erosion at Rincón, Puerto Rico, Thieler et al. (1995) calculate erosion rates using EPR, OLS, JK, and AOR in the Digital Shoreline Analysis System (DSAS, http://woodshole.er.usgs.gov/project-pages/dsas/). They divide their study site into four separate areas and calculate an average shoreline change rate at each section for each of the four methods. All four methods result in similar rates, but AOR is identified as the most appropriate shoreline change rate method at Rincón.

Dean and Malakar (1999) consider three shoreline change rate methods - OLS, EPR and AOR - in mapping Florida's hazard zones. They calculate correlation coefficients to compare the three methods. All three methods agree with each other; however, EPR and OLS correlate better with each other than either does with AOR. The authors choose OLS as their preferred method.

Fenster et al. (1993) introduce a new method, Minimum Description Length (MDL), 
as an alternative to existing methods. Based on Rissanen's (1989) MDL modeling criterion, this simplified version uses a complexity penalty to select the model that best fits the data (e.g., constant, linear, quadratic, etc.) with the fewest number of parameters. Crowell et al. (1997) compare predicted values from the MDL and OLS methods to actual values using sea-level data as a proxy for historical shoreline data. They conclude that OLS provides equal, if not better, results for shorelines without any physical modifications.

Differing from Crowell et al. (1997), Honeycutt et al. (2001) compare EPR to OLS by predicting known historical shoreline data, not sea-level data, to determine the accuracy of the methods. Using a priori knowledge of major storms, they confirm the findings of Galgano et al. (1998) and Galgano and Douglas (2000), which show that the accuracy of shoreline change rates improves without storm data points. They conclude that OLS better predicts shorelines than EPR. A good method to identify the best predictor involves using an earlier subset of shoreline positions to test forecasting of later positions (i.e., cross-validating). Our forecasting and hindcasting procedures follow those of Honeycutt et al. (2001). 


\section{CHAPTER 3 \\ ESTABLISHED EROSION RATE METHODS}

Dolan et al. (1991) provide an excellent overview of some of the published shoreline change rate methods. We expand their study to include other published methods, describing the advantages and disadvantages of each. The two most frequently cited methods are EPR and OLS, although most researchers now prefer OLS (Figure 1).

\subsection{End Point Rate (EPR)}

The EPR method uses only two data points to delineate a change rate - the earliest and most recent shoreline positions. Given that only the end data points are used, the information contained in the other data points is entirely omitted. The main disadvantage of this method is that if one or both endpoints are erroneous, the calculated erosion rate will be inaccurate (Crowell et al., 1997; Crowell et al., 1999; Dolan et al., 1991).

\subsection{Average of Rates (AOR)}

Shoreline positions are often defined from various sources (e.g., topographic surveys, coastal monument and beach profiles, and aerial photographs), each with its own measurement accuracy. For this reason, Foster and Savage (1989) developed the AOR method to average the long term change, excluding changes due to measurement errors (error and uncertainty are used interchangeably in the text). To do this, they created a minimum time criterion that filters out any changes due to short time spans or measurement errors. EPRs are determined between all data point pairs and are removed if the time interval is less than a specified minimum. All EPRs that pass the criterion are 
averaged to determine the shoreline change rate (Dolan et al., 1991; Foster and Savage, 1989). One drawback is that the minimum time criterion can be affected by large errors or small EPR, resulting in potentially misleading results (Dolan et al., 1991). AOR also gives more weight to recent changes in shorelines (Fenster et al., 1993). For these reasons, Foster and Savage (1989) recommend confirming AOR results with other shoreline change rate methods such as OLS.

\subsection{Minimum Description Length (MDL)}

As short-term changes may affect long-term trends, Fenster et al. (1993) propose a simplified form of the MDL method to help identify influential short-term changes. Assuming Gaussian errors, MDL utilizes an error component and a complexity penalty to select the best model fit, whether it is a constant, line, quadratic, etc. If the resulting model is quadratic or higher, two lines are produced - the zero-weight line (MDL ZERO), which uses only recent data, and the low-weight line (MDL LOW), which assigns weights to older data. MDL rates based on non-linear models tend to result in variable or highly inaccurate forecasts, though the MDL criterion can help identify physical changes within a beach (Crowell et al., 1997).

\subsection{Ordinary Least Squares (OLS)}

Least squares regression assumes independent Gaussian errors, and estimates the trend of shoreline data by minimizing the sum of the squared residuals between the data and line. The estimated parameters $\left(b_{0}-\right.$ intercept, $b_{1}-$ slope $)$ are those that minimize 
$\sum_{i}\left(y_{i}-b_{0}-b_{1} x_{i}\right)^{2}$. The assumption of Gaussian errors is usually valid, since the sum of many sources of error, as occur in these studies, tends to a Gaussian distribution. However, outliers that violate the Gaussian assumption will bias the apparent trend (Seber and Lee, 2003). A priori knowledge of non-Gaussian data points (e.g., storm points) can be used to eliminate such points. Ordinary least squares assumes homoscedasticity (e.g., Kleinbaum et al., 1998), which means that the variance of each Y-component (shoreline position) is the same.

This method is easy to code and many software companies include OLS as a tool in their spreadsheet programs. A number of statistical tests have been developed (e.g., ANOVA) to determine the goodness of the fit and to calculate confidence intervals around the line, future position, and shoreline change rate. These tests require near Gaussian statistics, which are derived from data scatter rather than independent sources.

A linear fit provides a long-term trend over the years for which data is available, but shorelines do not recede or accrete in a uniform manner, which raises questions about the appropriateness of linear models (Douglas et al., 1998; Fenster and Dolan, 1994; Fenster et al., 1993; Morton, 1991). Also, sediment supply and transport, presence of engineered structures, and storms may not result in Gaussian variations in the data (e.g., Fenster et al., 1993; Galgano and Douglas, 2000; Galgano et al., 1998; Honeycutt et al., 2001). Clustering of data in time greatly affects the trend line by causing some points to have undue influence (Dolan et al., 1991; Fenster et al., 1993). Since the line fit does not incorporate the uncertainty of each data point, the uncertainties of future shoreline positions may not reflect the data accurately. For example, according to Rousseeuw and 
Leroy (1987), this method is sensitive to outliers; often only one point is needed to distort the trend. If an outlier exists within a data set (e.g., storm point that violates the Gaussian assumption), the resulting line may be highly influenced by that one point. A priori knowledge is therefore important, yet controversial (e.g.,Fenster et al., 2001; Galgano and Douglas, 2000; Galgano et al., 1998; Honeycutt et al., 2001; Zhang et al., 2002).

\subsection{Jackknifing (JK)}

The jackknifing method uses multiple OLS fits to determine the shoreline change rate. A different point for each line is omitted, resulting in a different slope for each line. The slopes are averaged to provide a shoreline change rate. Jackknifing has the advantage of decreasing the influence of clustered data and extreme data points. However, computing all possible linear trends is not efficient (Dolan et al., 1991).

\subsection{Reweighted Least Squares (RLS)}

Given that storms and wave conditions in Hawai ${ }^{i} i$ impact different parts of the islands with varying effects, Rooney (2002), Rooney et al., (2003), and Fletcher et al. (2003) determine that RLS helps identify the true trend of shoreline change data by removing statistical outliers in the data. This two-step method first identifies outliers at a cut-off value ( $\hat{\sigma}$ ) using the Least Median of Squares (LMS) regression (Rousseeuw and Leroy, 1987). Points identified as statistical outliers are given a weight of 0 and all other points are assigned a weight of 1 . An OLS fit then finds the trend with all data points of weights equal to 1 . Unlike OLS, RLS is more robust and not as sensitive to outliers. 
RLS has a breakdown of $50 \%$ (that is, if $50 \%$ of the data are outliers, the trend of the data can still be identified accurately) (Rousseeuw and Leroy, 1987). As most shoreline studies have a limited data set, the removal of two or three points without any prior knowledge runs an undesirable risk of discarding 'good', but noisy, data. Also, adjacent transects along a beach (spaced $20 \mathrm{~m}$ in our case) do not always identify the same year as an outlier. This can lead to significant alongshore variations in modeled shoreline rates that are inconsistent with natural beach dynamics. Thus, this method probably works best with a large amount of data or if data from adjacent transects are binned (discussed later), so that true outliers are more evident. 


\section{CHAPTER 4 \\ NEW EROSION RATE METHODS}

In addition to the established methods discussed above, we explore three new methods to calculate shoreline change rates. These methods are based on wellestablished theoretical frameworks and are more robust than the least square methods described above (Figure 2).

\subsection{Weighted Least Squares (WLS)}

Unlike OLS, WLS assumes heteroscedastic uncertainties. This means that the variance associated with each $\mathrm{Y}$-component (shoreline position) is not necessarily the same at each X-component (time) (e.g., Kleinbaum et al., 1998). If the variances are the same, WLS reduces to OLS (Graybill and Iyer, 1994). In many studies it may be difficult to quantify the uncertainties for WLS; however, if the variance $\left(\sigma^{2}\right)$ or standard deviation $(\sigma)$ for each Y-component is known, the weight $(w)$ is equal to $1 / \sigma^{2}$. In matrix form, solving for $b$, a column vector with unknown parameters of intercept and slope, results in:

$$
b=\left(X^{T} W X\right)^{-1} X^{T} W Y
$$

in which $Y$ is a column vector containing shoreline positions, $X$ is a matrix composed of a column of ones and a column of time data, and $X^{T}$ is the transpose of the matrix $X$, (e.g., Draper and Smith, 1998). The weight matrix, $W$ is: 


$$
W=\left[\begin{array}{cccc}
w_{1} & 0 & 0 & 0 \\
0 & w_{2} & 0 & 0 \\
0 & 0 & w_{3} & 0 \\
0 & 0 & 0 & w_{n}
\end{array}\right]
$$

where $w_{i}=1 / \sigma_{i}^{2}$ and $n$ is the total number of data points (e.g., Graybill and Iyer, 1994).

Data points with large variance will have less of an influence on the trend line than data points with smaller variance (Graybill and lyer, 1994). For example, early shoreline data have larger uncertainties associated with them than recent shorelines. WLS will put more weight on the recent data. The resulting trend line incorporates the uncertainty at each position as well as the uncertainty of the model. Since all other assumptions for WLS equate with OLS (e.g., Gaussian errors), statistical tests and calculation of confidence intervals associated with OLS can also be performed on WLS (Kleinbaum et al., 1998).

In order to apply this method, it is necessary for researchers to estimate all uncertainties associated with their study. As with OLS, this method is sensitive to outliers even if their weights are small. Hence, a priori knowledge is also important. The drawbacks of assuming a Gaussian distribution as discussed in the OLS section also apply to WLS. If the calculated uncertainties at each shoreline position do not accurately express the real deviations, then the resulting rate may under- or over-estimate the true rate. 


\subsection{Reweighted Weighted Least Squares (RWLS)}

RWLS is similar to RLS except that it takes into account the uncertainties of each shoreline position. After identifying and removing outliers using LMS, a WLS line is fit to the data. Like WLS, RWLS incorporates positional uncertainties into the rate.

\subsection{Least Absolute Deviation (LAD)}

Least absolute deviation is more robust with respect to outliers than least squares. Unlike the squared residuals of least squares, the sum of the absolute value residuals in LAD is minimized (i.e., misfit function is $\sum_{i}\left|y_{i}-b_{0}-b_{1} x_{i}\right|$ ). As the residuals are not squared, an extreme value has less effect in LAD than in least squares. The assumed distribution of measurement errors is a two-sided exponential (Laplace) distribution, rather than a Gaussian, and the Laplace distribution's longer tails make it less sensitive to outliers (Tarantola, 1987). In comparing robust estimators, Rousseeuw and Leroy (1987) state that LAD is preferable over least squares methods when outliers are in the $y$ direction, which is the case in nearly all historical shoreline analyses.

Calculating the LAD estimate is not as straightforward as it is with least squares. A grid search is performed to calculate a misfit over a range of slopes and intercepts. The best fitting line is the one whose slope and intercept minimize the misfit. For example, an intercept, $\underline{b}_{0}$, that ranges from -2 to 2 with increments of 0.5 , and slope, $\underline{b}_{1}$, that ranges from 0 to 2 with increments of 0.25 identifies a minimum misfit of 3.65 . The slope and intercept estimates are 0.50 and 0.00 , respectively (Table 2 ).

The uncertainty calculation for the slope estimate is more difficult than that of least 
squares. To obtain a range of slopes at a certain percentile we first calculate an estimator of standard deviation (analogous to the root mean square error in least squares) and use it to compute the likelihood function, which in this case is the joint probability density function (pdf) of both the slope and intercept. The marginal pdf of the slope is obtained by integrating the joint pdf over intercept. The marginal pdf then gives the slope range at the percentile of interest. Unlike least squares, the slope range is not necessarily symmetrical around the peak of the slope pdf.

The major advantage of LAD is its robustness with respect to outliers. Similar to WLS, weights can also be incorporated in LAD (weighted least absolute deviation, or WLAD). As there are only two parameters, LAD is not difficult to code. Care must be taken in selecting a range of slopes and intercepts to search from when using the grid search. If the range is not broad enough, or point spacing not dense enough, the resulting estimates of slope and intercept might not reflect the data accurately; however, the algorithm can be made self-checking and self-adjusting to overcome this minor difficulty. 


\section{CHAPTER 5 \\ HAWAIIAN DATA AND UNCERTAINTIES}

To calculate shoreline change rates in Hawai ' $i$, we digitize the toe of the beach as our shoreline position on images taken in different years (Fletcher et al., 2003). The beach toe, which approximates the low water line, has been found to be a superior feature for shoreline change analysis along Hawaiian coastlines (Coyne et al., 1999; Fletcher et al., 2003; Rooney and Fletcher, 2000).

Several sources of error influence the delineation of shorelines. For example, aerial photographs taken at various tide levels influence the location of the digitized shoreline, which in turn, influences the resulting shoreline change rate. For our data, Fletcher et al. (2003) made a special effort to identify and quantify all errors in order to assess the 1- $\sigma$ uncertainty of a shoreline position. The errors are squared and summed to get a total positional uncertainty. We assume the total uncertainty follows a Gaussian distribution, since the Central Limit Theorem states that the sum of multiple sources of uncertainty of arbitrary distributions tends toward a normal distribution (Draper and Smith, 1998).

We use two different types of images to generate our shoreline positions topographic surveys (NOAA T-sheets) and vertical aerial photographs. Only T-sheets that pass the National Map Accuracy Standards are used in this analysis (Fletcher et al., 2003). The original surveyors of these T-sheets designated the Mean High Water Line (MHWL) as the shoreline position. We offset the MHWL in T-sheets to the low water line interpreted on aerial photos.

Following Fletcher et al. (2003) and Rooney et al. (2003), we calculate the total positional uncertainty $\left(U_{t}\right)$ using the equation: 
$U_{t}= \pm \sqrt{E r^{2}+E d^{2}+E p^{2}+E t s^{2}+E t d^{2}+E s^{2}+E c^{2}}$, where $E r=$ rectification error, $E d$ $=$ digitizing error, $E p=$ pixel error, $E t s=$ error plotting on a T-sheet, $E t d=$ tidal fluctuation error, $E s=$ seasonal error, and $E c=$ error in converting from MHWL to low water line on a T-sheet. Errors for T-sheets include Ets and $E c$, and exclude $E r$ and $E t d$. Aerial photographs do not include Ets and Ec. 


\section{CHAPTER 6}

METHODS

\subsection{Forecasting and Hindcasting (Cross-validation)}

Following Honeycutt et al. (2001), we compare the shoreline change rate methods discussed earlier by predicting known shoreline positions. For each prediction we calculate the difference between the actual and predicted position for all nine methods. Honeycutt et al. (2001) refer to this difference as the error in prediction (EIP) and describe the mean absolute EIP, (or mean $|\mathrm{EIP}|$ ) as a way of representing the magnitude of the error. In comparing the mean $|\mathrm{EIP}|$ for all the methods, we perform an ANOVA test at a $95 \%$ confidence interval to identify the differences. To compare the results of differing beach dynamics on Maui, we make forecasting predictions on two types of beaches - those with and without engineered (or hardened) structures. We make hindcasting predictions to check the validity of our earliest T-sheet points.

We compare EIPs of predictions that include a priori outliers to EIPs of predictions exclusive of these outliers. Determining a priori outliers is difficult in an island setting where different parts of the island are exposed to varying weather conditions (Fletcher et al., 2003). We therefore classify three regions on Maui - Kihei, West Maui, and the North Shore - as each having its own distinct wave regime (Fletcher et al., 2003; Rooney et al., 2003) (Figure 3).

We use previous research and historical accounts to determine $a$ priori outliers. Tide gauge data are used to confirm storm events for the North Shore only. From tide data and historical accounts of a devastating tsunami, we consider the 1960 shoreline to be an outlier for the North Shore. We similarly conclude that the 1963 shoreline is an outlier 
for West Maui due to kona storms based on the work of Eversole and Fletcher (2002) and is also an outlier in the Kihei region due to kona storms based on Rooney's (2002) study. Kona storms are low pressure systems that generate high winds and waves from the south and occur mostly in winter.

As Honeycutt et al. (2001) point out, predictions of the near future have lower error than predictions of the distant future. Also, if fewer data are available for a prediction, it will have large error. Another difficulty of forecasting analysis is that shoreline positions are not precisely known. Since all shoreline positions are subjected to errors inherent in aerial photogrammetry and T-sheets, the true positions are unknown. Instead, an estimate of the position is known and an estimate of the range of possible values is made. In comparing a measured position with a prediction, the uncertainties of each should be kept in mind. The predicted point might not equal the measured position, but remains a good prediction because it falls within the uncertainty of the measured point. Hence, whether one method provides a better prediction over another is affected by random errors in the point being predicted.

\subsection{Synthetic Beach Time Series}

Synthetic beach time series provide an alternative to hindcasting and forecasting. With synthetic time series, the calculated change rates of each method are compared to an assigned rate. To do this, we first assign a true slope and use this to calculate a database of synthetic shoreline positions at 8 discrete years. We then introduce noise to the shoreline database and use this noisy data to calculate change rates using the various 
methods. We repeat this process 1000 times while keeping the true rate constant, but varying the noise. Noise, in this case, is the scattering of the shoreline position based on the known uncertainties and an additional unknown factor. The unknown factor makes our knowledge of the shoreline position less certain. Hence, the generated noise in the synthetic analysis is greater than the uncertainty of the model in real data. Noise is created by sampling from a probability density function associated with each major uncertainty component that we quantify. For example, we quantify a rectification uncertainty based on the aerial photo ortho-rectification process. This has several independent errors associated with it, such as lens distortion, camera tilt, earth curvature, and terrain relief. We assume that a Gaussian distribution is the underlying distribution for the rectification error due to the Central Limit Theorem (Draper and Smith, 1998) and sample from this distribution to represent noise caused by the rectification process.

To account for any additional uncertainties that are not part of the shoreline analysis, we also generate noise from a Laplace, or two-sided exponential, distribution and add it to each shoreline position. We sample from each uncertainty distribution and add the samples together to get a total noise value for each synthetic data point. We calculate a change rate for every synthetic time series and make a histogram of all the calculated rates to see which method consistently is closest to the true value.

To compare the methods, we use the Kolmogorov-Smirnov test (hereafter K-S test) to determine whether two distributions of calculated change rates are significantly different (the Gaussian assumption is not needed to use the K-S test). The K-S test is sensitive to the mean, standard deviation, and shape of each distribution (Siegel, 1956). Thus, this 
test shows whether different rates methods give statistically indistinguishable predictions. If more than one method has indistinguishable predictions, the choice of method is left to the discretion of the analyst. To test the methods at different noise levels, we calculate rates with synthetic data twice - one set of data with less noise and the other with more noise. In the less-noise calculation, we sample from each uncertainty distribution that has a standard deviation that is equal to the average of the source of error plus a Laplace distribution with a standard deviation of $10 \mathrm{~m}$. For the calculation of rates with more noise, we use the maximum value of each source of error component and the Laplace distribution with a standard deviation of $20 \mathrm{~m}$.

We also compare methods when an extreme outlier exists, such as a storm shoreline. As it is difficult to identify a priori outliers at specific beaches, we want to identify methods that best determine the actual rate with the inclusion of an extreme nonGaussian point. We first add noise from a Laplace distribution with a standard deviation of $100 \mathrm{~m}$ to a middle data point (specifically, the $4^{\text {th }}$ position) and then repeat the above process of calculating a change rate 1000 times. We then add extreme noise to the last point and repeat the above process. A KS test is also performed on the resulting distribution of rates. Similar to the synthetic data without a storm point, we compute two different data sets - one with less noise and one with more noise, which is calculated in the same manner as mentioned in the preceding paragraph.

\subsection{Hawaiian Beaches and Binning of Shoreline Data}

We calculate change rates from shore-normal transects spaced $20 \mathrm{~m}$ alongshore. 
Individual transects contain between 5 to 9 unevenly spaced points spanning ca. 100 years. These datasets are typically limited and characterized by large data scatter. To reduce the effect of natural data variation from transect to transect and measurement errors, we bin data onto one plot from adjacent transects belonging to a contiguous stretch of beach and calculate change rates using the RWLS method. As the whole beach does not necessarily behave in the same manner, we need to identify sections of the beach that are indistinguishable. Importantly, transects that have engineered structures and no beach fronting them are removed from this analysis because most coastal managers define these areas as having no erosion or accretion, and their inclusion will unduly influence rates calculated along the rest of the beach.

To identify which transects should be binned together and thus represent a section of beach where erosion rates are indistinguishable, we group adjacent transects and compare their combined rate to the combined rate of all other transects on that beach. The reader is referred to Figures $4-8$ for a graphical illustration of the binning process. We start with a window spacing of 4 transects (Figure 4) and group the first four adjacent transects together and then calculate the rate. We compare this rate to the rate of a bin of the remaining transects using a Student's t-test (Kleinbaum et al., 1998) at a 95\% confidence interval to determine any disagreements (Figure 4). The window is then shifted over by one transect and a new t-test is performed. The window continues shifting by one transect until the last four transects are grouped together. Each time the window shifts, a $\mathrm{t}$-test is calculated to compare the grouped transects within the window to the binned rate of the rest of the transects. The window size is then increased from 4 transects to 6 and 
the process of calculating a t-test is repeated. The window size is increased and the binning procedure is repeated until we reach a window size equal to ( $\mathrm{n}$ transects)/2. When the binning procedure is complete, clusters of transects are identified by executing a Student's t-test on groups of transects that are found to be statistically different from the rest of the beach. Within each window size, a t-test is performed on any overlapping transects (Figure 5). If the overlapping transects are statistically not different, then they are grouped together as one bin (Figure 6A). If they are different, then they are grouped separately (Figure 6B). Another t-test is performed to determine whether the bins at each window size are statistically different from bins of other window sizes that have overlapping transects. Bins that are found to be statistically not different are clustered together and a rate is calculated for that region (Figure 7). For visual purposes, each cluster is assigned a color and each transect within a cluster is allotted a shade (Figure 8). The shade depends on the frequency of windows that intersect a given transect - transects that contain a higher frequency of windows that belong to the same cluster will be a darker shade than transects that have a lower frequency of windows. For example, in Figure 7, transect \#57 has 27 windows that intersect it, while transect \#51 has only 3 intersecting windows. As a result, transect \#57 will be darker than transect \#51 (Figure 8). Transects that encompass more than one cluster will have a mixed color value. 


\section{CHAPTER 7}

\section{RESULTS}

\subsection{Rate Method Comparisons}

The prediction analysis (forecasting and hindcasting) use real data to compare shoreline change rate methods. Although many caveats are associated with this analysis, forecasts and hindcasts suggest how well each rate method predicts future real data. On the other hand, the advantage of using the synthetic analysis is that the true synthetic rate is known, so the error of the predicted rate is also known. However, this analysis uses manufactured rather than real noise and assumes that errors are additive. Both prediction and synthetic results agree that MDL and AOR provide the least desirable results, and OLS, WLS, RLS, RWLS, JK and LAD are valid methods under certain conditions.

\subsubsection{Forecasts}

Excluding the North Shore, forecasts of positions with hardened structures have lower $|E I P|$ than forecasts of positions free of hardened structures. The North Shore predictions (Tables 3-4) with the 1960 storm position have considerably higher |EIP|, which can be attributed to one beach where predictions made from T-sheets and 1960 positions did not reflect actual positions (Figure 9). Generally, predictions from OLS, WLS, RLS, RWLS, JK, EPR, an LAD are statistically not different and have the smallest $|\mathrm{EIP}|$. AOR and MDL are continuously singled out as methods that are significantly different from other methods because they show appreciably higher |EIP| (Tables 3-4).

Predictions improve for all methods when a priori outliers are removed from the dataset. This improvement ranges from $<0.1 \mathrm{~m}$ to $15 \mathrm{~m}$. Geographically, the most improvement occurs on the North Shore with hardened structures. MDL and AOR 
improve more than other methods when outliers are removed (average not including North Shore $=3.6 \mathrm{~m}$ ). The storm points negatively influence MDL and AOR predictions. All least squares methods, JK and LAD, on the other hand, have minimal improvements when a priori outliers are removed for all regions (average improvement excluding the North Shore $=0.7 \mathrm{~m})$.

\subsubsection{Hindcasts}

The hindcasting mean $|E I P|$ is slightly larger than that of forecasts (Tables 4-5). This increase is due to large uncertainties and lack of detailed information that surrounds Tsheets. Hindcasts of beaches with hardened structures have lower mean $|\mathrm{EIP}|$ than beaches without hardened structures (excluding the North Shore). The hardened structures consist of seawalls, groins, and revetments, which may stabilize the beach on a short-term basis. Similar to forecasts, MDL and AOR hindcasts have high mean $|\mathrm{EIP}|$ and generally do not reflect the results of all other methods.

Removing a priori outliers improves hindcasts minimally. Hindcasts of West Maui improve by only $1 \mathrm{~m}$ when storms are removed. Hindcasts of the North Shore with hardened structures are less accurate by an average of $2.4 \mathrm{~m}$ without storm points (individual beaches have even a greater negative difference). This decrease in accuracy could be attributed to the storm outlier having no negative influence on the trend; hence, it is not a true storm outlier for that area. All other areas, however, show marked improvement when a priori outliers are excluded. AOR has the biggest improvement in hindcasts when storms are removed.

\subsubsection{Synthetic Data}


Three sets of synthetic data were generated - one with no storm outlier, one with a storm outlier in a middle position, and one with a storm outlier at the last position. For each set, two runs were made - one with less noise and one with more noise. A SiegelTukey test that tests the significance of two standard deviations was also calculated for all rate methods. The results of the Siegel-Tukey test concur with the K-S test results.

\subsubsection{Time Series Without a Storm Point}

K-S test results of time series with less noise show that WLS, RWLS and WLAD predictions are not statistically different at the $95 \%$ confidence interval, but are statistically different from all other methods (Table 7A). WLS, RWLS and WLAD also have the smallest standard deviations, or data spread, and thus provide better predictions (Figure 10). K-S test results of time series with more noise show that all methods except for AOR and MDL perform equally well and are not significantly different from each other (Table 7B). AOR and MDL distributions have high spreads compared to all other methods (Figure11).

\subsubsection{Time Series with Storm in Middle Position}

K-S test results of data with less noise demonstrate that methods other than AOR and MDL are not statistically different (Table 7C). The spreads of MDL and AOR are higher than all other methods (Figure 12). For data with more noise, the K-S test results show that OLS, WLS, RLS, RWLS, JK, and WLAD are not statistically different (Table 7D). EPR and LAD are statistically different from other methods, but not statistically different from each other. EPR and LAD also have higher spreads than other methods, excluding AOR and MDL. AOR and MDL are statistically different from all other methods and 
have the highest spreads (Figure 13).

\subsubsection{Time Series with Storm in Last Position}

K-S test results of data with less noise show that RLS, RWLS, LAD, and WLAD are not statistically different and have the lowest spreads (Table 7E). OLS, WLS, and JK do not have statistically different distributions from each other, but have higher spreads than RLS, RWLS, LAD, and WLAD. EPR, AOR, and MDL have much higher spreads (Figure 14). When more noise is added to the time series, K-S test results show that all methods except for EPR, AOR, and MDL are not statistically different (Table 7F). EPR, AOR and MDL have higher spreads than all other methods (Figure 15).

\subsection{Binning}

Based on both the forecasting and synthetic time series results, we choose to bin data using the RWLS method. RWLS is chosen because we are confident in our knowledge of the major uncertainties in our shoreline methodology and are not confident of the identification of storm outliers. Binned rates and their uncertainties are better resolved than unbinned rates and their uncertainties. $84 \%$ of the trends of binned rates are significant, whereas only $38 \%$ of the trends of unbinned rates are significant. There is a $0.1 \mathrm{~m}$ decrease in uncertainties with binned rates compared to unbinned rates. In both instances, the binned rates and uncertainties are better constrained than the unbinned rates and uncertainties. We perform the binning analysis on 15 beaches -8 from Kihei, 4 from West Maui, and 3 from the North Shore. The 8 beaches of Kihei display 2 different patterns and are further categorized into 2 geographical groups within this study site - 4 central beaches and 4 southern beaches (Table 8 ). 
Kihei is sheltered from waves by Kahoolawe and Lanai islands, but is subjected to south swells, refracted north swells and kona storm waves. No fringing reef is present in our study area (Fletcher et al., 2002; Makai Ocean Engineering and Sea Engineering, 1991; Rooney and Fletcher, in press). The central beaches in Kihei behave uniformly. Only one of these central beaches contains a seawall but all four have significant erosion. The southern beaches depict distinct behaviors between their northern and southern sections (Table 8).

West Maui beaches are affected by North Pacific swells, south swells and kona storm waves. North Pacific swells do not severely impact this area because it is located in the shadow of Molokai island (Eversole and Fletcher, 2003; Fletcher et al., 2002). Segments of the shoreline in this area contain fringing reefs and only one beach has a seawall (Eversole and Fletcher, 2003; Makai Ocean Engineering and Sea Engineering, 1991). West Maui study sites depict a pattern of erosion at one end of each beach and either minimal erosion or accretion at the other end (Table 8).

North Shore beaches are influenced by North Pacific swells and tradewind waves. Fringing reefs are widespread in this area (Fletcher et al., 2002; Makai Ocean Engineering and Sea Engineering, 1991). The North Shore study area illustrates distinct behaviors between eastern and western sections of each beach. Two of the three beaches have engineered structures - one has 5 groins and one has an offshore rock platform with an onshore revetment. These two beaches exhibit more erosion than the beach without any structures (Table 8 ). 


\section{CHAPTER 8}

DISCUSSION

\subsection{Comparisons of Rate Methods}

Based on our synthetic work and prediction analysis, we advise analysts to determine how well they understand the uncertainty in their methodology before picking the best erosion rate method. When uncertainties are mostly understood, weighted methods are recommended; conversely, if uncertainties are poorly understood, OLS, RLS, JK, or LAD are recommended. If doubt exists on the Gaussian nature of the uncertainty, LAD and WLAD are recommended. We are confident in our understanding of the major uncertainty components in our shoreline assessment study; however, we are not confident in our assessment of storm outliers. As stated earlier, Hawai' $i$ is an island state and different beaches are affected differently by storms. The difficulty in identifying a priori outliers, together with the results from the synthetic storm analysis and the prediction analysis, are the basis for choosing RWLS as the most robust method for Hawai ${ }^{\circ} \mathrm{i}$.

In synthetic data sets with less noise, the weighted methods are far superior to all other methods. This superiority disappears as noise increases. As more noise is introduced to the data, the weights no longer reflect the uncertainty, and other methods that put more emphasis on the uncertainty in the model achieve better results. OLS, RLS, $\mathrm{JK}$, and LAD out-perform weighted methods when noise is sampled solely from a Laplace distribution. If, however, the majority of uncertainty components are known, weighted methods reflect the true process better (see Table 7A).

Results vary when storm points are added to middle and end positions of synthetic data. The results with a storm in the middle are similar to results containing no storm 
point. The bias created by the storm at the middle position is not as detrimental in finding the long-term trend as the bias with a storm at the end position. This is because an end point is a leverage point that can influence the trend of the model more than interior points. With the storm at the end position, WLS, OLS, and JK do not perform as well as RLS, RWLS, WLAD and LAD. Since WLS, OLS and JK do not identify statistical outliers and the storm point is at a leverage position, the storm point unduly influences the results. RWLS and RLS remove statistical outliers, and LAD and WLAD are less susceptible to outliers in the y-direction (Rousseeuw and Leroy, 1987); hence, they perform better than all other methods when a storm point exists at the end position. When noise increases, however, all methods perform similarly, except for EPR, AOR, and MDL (Table 7F).

Forecasting results show that in most cases, methods with the highest mean $|E I P|$ are statistically different from methods with lower mean |EIP|. OLS, WLS, RLS, RWLS, $\mathrm{EPR}$, and LAD consistently have the lowest EIP and are insignificantly different from each other.

MDL and AOR have the highest mean $|\mathrm{EIP}|$. Their predictions also have the most improvement when storm outliers are removed. Both methods put more influence on short-term trends and remove data from the rate calculation. The end point rate combinations that have a storm point as an end point in AOR might be weighted strongly in the AOR rate. Once the storm is removed from the data, AOR predictions improve. These are still less effective than the least squares methods, since AOR depends on the minimum time criterion, which decreases the number of EPRs available for averaging. 
MDL ZERO predictions are comparable in accuracy to those of AOR. The zero-weight line of MDL often discards early shoreline positions that don't fit the pattern of the most recent trend of the data. Predictions made with the most recent trend are more variable than predictions made with a longer-term trend. Removing the storm points affect the more recent trends and result in improved, yet still variable predictions. MDL LOW has better predictions than MDL ZERO because it does incorporate the early shoreline positions, which agrees with Crowell's et al. (1997) results. The predictions with the low-weight line do not always perform as well as the least squares because they still give more weight to the more recent data points.

When comparing forecasts with hardened structures to forecasts without hardened structures, the mean $|\mathrm{EIP}|$ for hardened structures is reduced in all cases, except for the North Shore. This reduction is similar to that of the hindcast results. In all areas, except for the North Shore with hardened structures, predictions exclusive of storm data improve only slightly and are insignificant in most cases. For the North Shore with hardened structures, the mean $|\mathrm{EIP}|$ is extremely large $(>20 \mathrm{~m}$ ) when the 1960 storm (in this case, tsunami) position is present. Looking at individual beaches on the North Shore, the mean |EIP| for Kanaha shows no improvement when removing the 1960 tsunami point (Table 9). Kahului, on the other hand, is responsible for the large mean |EIP|. The Kahului analysis is composed of three early T-sheets $(1899,1912$ and 1929), and five aerial photo positions $(1960,1975,1988,1997$ and 2002). All but one set of predictions in Kahului is comparable to predictions from Kanaha. The one set of predictions that behaves differently in Kahului consists of three T-sheet points and one 1960 aerial position, which 
account for the large mean $|\mathrm{EIP}|$. This is due to the fact that the erosion rates from these points indicate accretion or minor erosion. However, erosion averaged $2.80 \mathrm{~m} / \mathrm{yr}$ between 1960 and 1975. This significant increase in erosion resulted in predictions that do not reflect the actual positions (Figure 9). Comparing the results without this set of predictions reveals that all methods, excluding MDL, do not improve significantly when the 1960 position is taken out (Table 10). When segmenting the study area into individual beaches, some beaches have no significant improvement at the $95 \%$ confidence interval when storm outliers are removed, while other beaches do. This could be due to differing storm or tsunami effects. Some beaches are protected from the full force of the waves by surrounding islands or fringing reefs, while others are more exposed.

The EIPs for hindcasts are somewhat greater than those of forecasts. This is because T-sheet positions usually have greater uncertainties than aerial photos $( \pm 7-10 \mathrm{~m})$. Hindcast predictions that are less than $10 \mathrm{~m}$ away from the true position are still within the uncertainty bounds of the true positions. The difference between the predicted point and the true point with its uncertainty thus reduces to a maximum of $10 \mathrm{~m}$ (excluding the North Shore). We calculate a $95 \%$ confidence interval uncertainty around the predicted positions (Table 11). The minimum average uncertainty of the predicted positions is 15 m. By incorporating the uncertainties of both the true and predicted positions, even the North Shore predictions fall within the uncertainty bands. Also, removing storms does not much improve the hindcasts - 10 of the 13 beaches show no significant improvement, one shows significant improvement with half the methods, one beach shows significant 
improvement and one beach shows significantly worse predictions. For the beach that shows statistically significant improvement, the improvement is not greater than the uncertainty surrounding both the predicted and actual positions. Thus, early $20^{\text {th }}$ century T-sheet positions are valuable in the shoreline change rate analyses.

\subsection{Outliers}

We investigated two types of outliers and their influence on the accuracy of predicting shoreline behavior: (1) a priori outliers based on historical data, such as a tsunami, hurricane, or storm event; and (2) outliers based on residual statistics.

The time necessary for a shoreline to recover from a major erosional event can vary (Zhang et al., 2002), resulting in non-Gaussian behavior. Zhang et al. (2002) argue that storms are independent of any long-term trend and should be considered separately because beaches eventually recover to their pre-storm positions. With limited data sets, such as individual transects that have only 5-8 points, an a priori outlier may unduly bias any calculation of a long-term trend. Zhang et al. (2002) support Douglas and Crowell's (2000) assertion that the most practical option is to remove these points. In our study, however, we identify two a priori outliers - the 1960 tsunami that affected the north shore of Maui and the 1963 kona storms. When we use the dataset to predict the position of a known shoreline at each beach, removing storm shorelines improves our prediction by an average of $1.1 \mathrm{~m}$ (least squares), with the exception of one beach that experienced accretion during a storm event. This improvement is minimal when compared to Honeycutt's et al. (2001) results from U.S. east coast beaches, which demonstrate an 
improvement of 15-30 meters when a priori outliers are removed. We note, however, that carbonate beaches in general and Hawaiian beaches specifically tend to be much narrower than east coast beaches. An improvement of $1 \mathrm{~m}$ may represent $5 \%$ of the dry beach width in many cases. The cost of removing outliers from small datasets, typically used in erosion analysis, is usually an increase in the uncertainty of the calculated longterm trend. In the end, an analyst must weigh the cost of increased uncertainty against the benefit of improved predictive accuracy. We conclude that a priori outliers need to be investigated at each study site before deciding on their treatment.

Researchers currently do not remove outliers unless they can assign the points to some meteorological or geological factor. Statistical outliers, however, are critical components to consider when using least squares because of this method's susceptibility to outliers, especially for small datasets. A large deviation at a point causes a bias in the trend if there are few data points, and this can be amplified if the point is at a leverage position. Some studies have attempted to relate statistics, such as residuals, to outliers. Focusing on reducing the root mean squared error (RMSE), Galgano et al. (1998) state that storm-influenced residuals increase the error in the model fit and thus invalidate the model. They choose to use a priori information to remove these points, but the erosion rates with and without these points are not significantly different. Fenster et al. (2001) identify outliers by calculating studentized residuals and compare them to known storm dates. They find that none of the statistical outliers correspond to any known storms and advise not to remove them as outliers.

Fletcher et al. (2003) and Rooney et al. (2003) identify and remove statistical outliers 
differently. As mentioned earlier, the least median of squares (LMS) method is part of a two step process involving RLS or RWLS that calculates residuals (Rousseeuw and Leroy, 1987). They disregard a data point if a residual is greater than an assigned cut-off value $(\hat{\sigma})$. The cut-off value $(\hat{\sigma})$ is an estimate of the true standard deviation of a population $(\sigma)$, which is dependent on the sample size. For small sample sizes, there is less certainty in any estimate of the true $\sigma$, making the cut-off boundary less exact and causing the removal or retention of too many outliers. If the outlier analysis at adjacent transects identifies different points as outliers, the resulting erosion rates are also likely to differ, leading to the case where physically adjacent beach segments are assigned inconsistent long-term trends. In our dataset with an alongshore spacing of $20 \mathrm{~m}$, we find that adjacent transects do not behave independently of each other.

One way to utilize LMS is to increase the number of points used in the calculation of a trend, which can be done by binning data from adjacent groupings of transects and calculating a trend. Binning will reduce the spread, or uncertainty, around the cut-off value $(\hat{\sigma})$, which will improve the identification of outliers. Therefore, we recommend using a relatively large sample size to increase the signal-to-noise ratio and improve the estimate of the spread of the data $(\hat{\sigma})$ when removing statistical outliers.

\subsection{Binning Analysis}

Setbacks on Maui are currently based on erosion rates from transects spaced $20 \mathrm{~m}$ alongshore. Some adjacent transects have differing rates, which affect the setback location. Because only 5-9 historical shoreline positions are available, the noise in the 
data can mask the signal. One advantage of binning is that by spatially increasing our points, we decrease the noise by averaging out the random errors. This decrease in noise allows us to better identify a region of a beach that has indistinguishable rates (i.e., sublittoral cells) and assign it one rate. Temporally, our data is unchanged - we can only increase the number of temporal positions by adding more photographs or T-sheets. Coastal planners will then be able to use one rate to determine the setback for that subcell of beach.

When comparing trends of all beaches, the four central beaches in Kihei behave similarly. All four beaches are relatively small pocket beaches with well-developed backshores. Their location, in the shadow of the islands of Molokai, Lanai and Kahoolawe, protects them from high swells; however, kona storms have a history of inflicting great damage to this area (Fletcher et al., 2003; Rooney and Fletcher, 2000; Rooney and Fletcher, in press). In a study of net sediment transport on a stretch of armored beach just north of these beaches, Rooney and Fletcher (2000) conclude that tradewind waves cause southward movement of sediment, though a northward movement of sediment predominates due to kona storm activity. We do not see a similar net movement in sediment. Rather, a uniform manner of erosion is characteristic throughout each beach. This uniformity could be due to the relatively small size of the beach that is evenly affected by both kona storm waves and tradewind waves or that any movement is undetectable given the existing data sets and inherent uncertainties.

The southern beaches in Kihei are more susceptible to south swells and have more variability in binning results. These beaches are less developed and less eroded than their 
central counterparts. A cinder cone divides these four beaches into two northwest facing and two southwest facing beaches. A very small pocket beach on the south end of the cinder cone accretes uniformly. The cinder cone protects it from both north and south waves. The cinder cone also directly affects a pocket beach to the north of it and a longer pocket beach to the south. The central portion of the longer beach erodes uniformly, while the north end of the beach erodes faster and the south accretes faster. This is caused by interference of sediment transport by the headland. The pocket beach directly north of the cinder cone exhibits the most erosion in the central portion of the beach, while the northern section shows either minimal erosion or accretion. This follows Rooney and Fletcher's (2000) conclusion of net sediment transfer to the north.

Two of the three beaches on the North Shore have engineered structures that influence the results. The North Shore is affected by strong North Pacific swells in the winter and strong, consistent tradewind waves throughout the year. The western end of one beach contains 5 groins and is less erosive than the eastern portion of the beach because a groin at the eastern end of this beach reduces the amount of sediment delivery to the west of it. The groins were installed to slow the alongshore sediment transport to the west (Makai Ocean Engineering and Sea Engineering, 1991), but have caused extensive erosion. Another beach has an offshore rock platform and a revetment in the center of the beach that has caused great erosion on the eastern end of the beach.

We compare our binning results (Figure 16) to Eversole and Fletcher's (2003) study of sediment transport at Kaanapali Beach in Maui in order to relate annual transport to multi-decadal observations. Eversole and Fletcher (2003) examine sediment transfer by 
longshore sand transport at the Kaanapali Beach littoral cell and conclude that transport of sand is northward in summer and southward in winter, although the net annual transport is northward. They identify an inflection point within the littoral system and demonstrate a seasonal volume shift at this position, which also approximates the net annual transport in this location. In our binned analysis, the same region is clustered together and identified as a group that is accreting. We find that this group differs from the southern portion of the beach, which is eroding long-term at a much faster rate. Although we are not able to identify seasonal fluxes, we do observe erosive south and accretive north sections that agree with Eversole and Fletcher's (2003) observation of net annual transport to the north.

\subsection{Erosion Hazard Maps}

Erosion hazard maps are useful in identifying setbacks that are used by coastal planners. Based on the results of our study, we have produced erosion hazard maps that reflect the trend of shoreline movements more accurately than previously used maps. These new maps incorporate uncertainties of the shoreline change rate methodology and identify binned regions of a beach. The drawbacks of these maps include assumptions of a linear shoreline behavior, with no change in long-term effects of storms.

There are three major steps coastal managers need to do in order to produce erosion hazard maps (Figure 17). The first is to identify a change rate method based on their data. The next step is to bin the data. For example, two bins are identified in Figure 18 one on the eastern end of the beach and one on the western end. Finally, transects of each 
bin are grouped together and the 50-year predicted position with a $1-\sigma$ uncertainty is identified by projecting the regression line into the future. The setback is calculated with 1- $\sigma$ confidence bands placed on either side of the setback, which creates a hazard zone. Maui County measures the setback from the certified shoreline. The vegetation line is

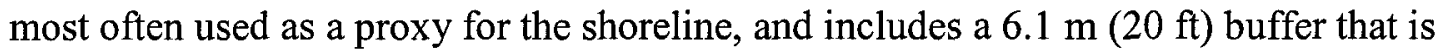
designed to partially compensate for method errors, storm and tsunami hazards, and nonlinear shoreline change. In our analysis, the 50 -year predicted position is calculated from low water line data; consequently a vegetation line offset and buffer are added to the future position before the setback is projected onto the map. 


\section{CHAPTER 9 \\ CONCLUSIONS}

By comparing the shoreline change rate methods and investigating outliers, we make the following conclusions. (1) OLS, RLS, WLS, RWLS, JK, LAD, and WLAD are preferred methods based on synthetic results and low $|\mathrm{EIP}|$ in forecasts. If major uncertainties in a methodology are known and quantifiable, WLS, RWLS, and WLAD better reflect the true process of the data. If uncertainties are unknown or not quantifiable, LAD is preferred, although OLS, RLS, and JK can be considered. If effects of storms are unknown or a priori outliers are hard to identify, RLS, RWLS, LAD, and WLAD are preferred. (2) We choose to use RWLS on Maui as our method based on our knowledge of uncertainties and our lack of confidence in identifying a priori outliers. (3) MDL and AOR produce the most variable results. (4) Early $20^{\text {th }}$ century T-sheets are valuable in shoreline change rate analysis. (5) Hardened shorelines reduce variability of beach behavior. (6) Increasing the number of data points via binning neighboring transects in a RWLS or RLS analysis improves the estimate of spread in data when identifying statistical outliers.

We conclude from the binning analysis that (7) binning adjacent transects improves the signal-to-noise ratio. The resulting binned rates reflect long-term sand transport within a littoral cell. 


\section{APPENDIX A: TABLES}

Table 1. Abbreviations in text.

\begin{tabular}{|ll|}
\hline EPR & End Point Rate \\
AOR & Average of Rates \\
MDL LOW & Minimum Description Length - Low weight line \\
MDL ZERO & Minimum Description Length - Zero weight line \\
OLS & Ordinary Least Squares \\
WLS & Weighted Least Squares \\
RLS & Reweighted Least Squares \\
RWLS & Reweighted Weighted Least Squares \\
JK & Jackknifing \\
LAD & Least Absolute Deviation \\
WLAD & Weighted Least Absolute Deviation \\
EIP & Error In Prediction \\
\hline
\end{tabular}


Table 2. An example of a misfit function for LAD. The values of the calculated cost function are in each box. $b_{0}=$ intercept and ranges from -2 to 2 with increments of 0.5 ; $\mathrm{b}_{1}=$ slope and ranges from 0 to 2 with increments of 0.25 . The minimum value is highlighted with a slope of 0.50 and intercept of 0 .

\begin{tabular}{|c|c|c|c|c|c|c|c|c|c|}
\hline & 0.00 & 0.25 & 0.50 & 0.75 & 1.00 & 1.25 & 1.50 & 1.75 & 2.00 \\
\hline $00-2.00$ & 22.36 & 16.86 & 11.56 & 7.72 & 6.51 & 7.62 & 10.77 & 16.14 & 21.64 \\
\hline-1.50 & 19.61 & 14.11 & 9.19 & 6.14 & 5.40 & 8.10 & 13.39 & 18.89 & 24.39 \\
\hline-1.00 & 16.86 & 11.36 & 7.24 & 4.69 & 5.55 & 10.64 & 16.14 & 21.64 & 27.14 \\
\hline-0.50 & 14.11 & 9.29 & 5.29 & 4.01 & 7.89 & 13.39 & 18.89 & 24.39 & 29.89 \\
\hline 0.00 & 11.74 & 7.24 & 3.65 & 5.75 & 10.64 & 16.14 & 21.64 & 27.14 & 32.64 \\
\hline 0.50 & 9.69 & 5.23 & 4.60 & 8.47 & 13.39 & 18.89 & 24.39 & 29.89 & 35.39 \\
\hline 1.00 & 7.64 & 5.25 & 6.95 & 11.22 & 16.14 & 21.64 & 27.14 & 32.64 & 38.14 \\
\hline 1.50 & 7.29 & 6.45 & 9.47 & 13.97 & 18.89 & 24.39 & 29.89 & 35.39 & 40.89 \\
\hline 2.00 & 8.18 & 8.47 & 12.22 & 16.72 & 21.64 & 27.14 & 32.64 & 38.14 & 43.64 \\
\hline
\end{tabular}


Table 3. Forecasts free of hardened structures. EIP = error in prediction. Mean $|\mathrm{EIP}|$ is the average magnitude difference between a predicted and known position. The mean $|\mathrm{EIP}|$ of all methods were compared by an ANOVA test. Methods containing 'yes' indicate statistically insignificant mean $\mid$ EIP $\mid$, while 'no' means statistically significant mean $|\mathrm{EIP}|$.

\begin{tabular}{|c|c|c|c|c|c|c|c|}
\hline Region & Method & $\begin{array}{r}\text { Mean } \\
\text { all points }\end{array}$ & $\begin{array}{l}\text { EIP (m) } \\
\text { w/o storms }\end{array}$ & $\begin{array}{c}\text { Mean }|\mathrm{EIP}|(\mathrm{m}) \\
\text { all points }\end{array}$ & $\begin{array}{l}\text { Statistically } \\
\text { Similar? }\end{array}$ & $\begin{array}{c}\text { Mean }|\mathrm{EIP}|(\mathrm{m}) \\
\text { w/o storms }\end{array}$ & $\begin{array}{c}\text { Statistically } \\
\text { Similar? }\end{array}$ \\
\hline \multirow{10}{*}{ Kihei } & $\overline{\text { OLS }}$ & 4.0 & 0.4 & 11.7 & yes & 9.3 & yes \\
\hline & WLS & 4.3 & 0.3 & 12.6 & yes & 9.9 & yes \\
\hline & RLS & 3.9 & 0.4 & 11.8 & yes & 9.3 & yes \\
\hline & RWLS & 4.2 & 0.3 & 12.6 & yes & 9.9 & yes \\
\hline & EPR & 4.2 & 0.4 & 12.5 & yes & 9.7 & yes \\
\hline & AOR & 7.8 & 0.8 & 19.0 & no & 12.7 & no \\
\hline & JK & 5.4 & 1.3 & 13.6 & no & 10.8 & no \\
\hline & MDL LOW & 9.0 & 0.2 & 20.3 & no & 12.4 & no \\
\hline & MDL ZERO & 16.3 & 2.5 & 29.8 & no & 16.8 & no \\
\hline & LAD & 3.8 & 0.8 & 11.7 & yes & 9.5 & yes \\
\hline \multirow{10}{*}{ West Maui } & OLS & -1.5 & -1.3 & 8.8 & yes & 8.5 & yes \\
\hline & WLS & -1.9 & -1.7 & 9.2 & yes & 8.7 & yes \\
\hline & RLS & -1.7 & -1.5 & 8.9 & yes & 8.6 & yes \\
\hline & RWLS & -2.1 & -1.8 & 9.3 & yes & 8.7 & yes \\
\hline & EPR & -0.7 & -0.5 & 9.6 & no & 8.8 & yes \\
\hline & AOR & -7.1 & -3.1 & 14.7 & no & 10.4 & no \\
\hline & JK & -2.3 & -2.1 & 9.6 & no & 9.3 & yes \\
\hline & MDL LOW & -2.5 & -2.8 & 9.8 & no & 9.0 & yes \\
\hline & MDL ZERO & -4.1 & -4.2 & 11.6 & no & 10.5 & no \\
\hline & LAD & -0.3 & -0.3 & 8.8 & yes & 8.7 & yes \\
\hline \multirow{10}{*}{ North Shore } & OLS & -1.8 & -0.9 & 5.2 & yes & 4.9 & yes \\
\hline & WLS & -1.4 & -0.8 & 5.1 & yes & 5.0 & yes \\
\hline & RLS & -1.8 & -0.9 & 5.2 & yes & 4.9 & yes \\
\hline & RWLS & -1.4 & -0.8 & 5.2 & yes & 5.0 & yes \\
\hline & EPR & -1.9 & -0.9 & 5.0 & yes & 4.9 & yes \\
\hline & AOR & -2.2 & -1.1 & 5.5 & no & 5.3 & yes \\
\hline & JK & -1.5 & -0.8 & 4.9 & yes & 4.8 & yes \\
\hline & MDL LOW & -1.5 & -0.7 & 5.1 & yes & 4.9 & yes \\
\hline & MDL ZERO & -0.7 & -0.3 & 5.6 & yes & 5.4 & yes \\
\hline & LAD & -2.0 & -1.0 & 5.0 & yes & 4.8 & yes \\
\hline
\end{tabular}


Table 4. Forecasts with Hardened Structures.

\begin{tabular}{|c|c|c|c|c|c|c|c|}
\hline Region & Method & $\begin{array}{r}\text { Mea } \\
\text { all point }\end{array}$ & $\begin{array}{l}\text { EIP }(\mathrm{m}) \\
\text { w/o storms }\end{array}$ & $\begin{array}{c}\text { Mean }|\mathrm{EIP}|(\mathrm{m} \\
\text { all points }\end{array}$ & $\begin{array}{l}\text { Statistically } \\
\text { Similar? }\end{array}$ & $\begin{array}{c}\text { Mean }|\mathrm{EIP}|(\mathrm{m}) \\
\text { w/o storms }\end{array}$ & $\begin{array}{c}\text { Statisticall } \\
\text { Similar? }\end{array}$ \\
\hline \multirow{10}{*}{ Kihei } & OLS & -1.6 & -2.2 & 7.4 & yes & 7.0 & yes \\
\hline & WLS & -1.8 & -2.4 & 7.7 & yes & 7.2 & yes \\
\hline & RLS & -2.0 & -2.2 & 7.7 & yes & 7.0 & yes \\
\hline & RWLS & -2.0 & -2.4 & 8.0 & yes & 7.2 & yes \\
\hline & EPR & -1.7 & -2.3 & 7.7 & yes & 7.1 & yes \\
\hline & AOR & -2.5 & -3.0 & 14.1 & no & 8.2 & no \\
\hline & JK & -2.0 & -2.5 & 8.5 & no & 7.4 & yes \\
\hline & MDL LOW & 1.1 & -2.7 & 14.1 & no & 8.2 & no \\
\hline & MDL ZERO & 2.1 & -3.3 & 18.6 & no & 10.1 & no \\
\hline & LAD & -1.7 & -2.1 & 7.2 & no & 6.8 & yes \\
\hline \multirow{10}{*}{ West Maui } & OLS & -3.3 & -3.3 & 6.0 & yes & 6.1 & yes \\
\hline & WLS & -3.8 & -3.8 & 6.2 & yes & 6.2 & yes \\
\hline & RLS & -3.4 & -3.3 & 6.1 & yes & 6.1 & yes \\
\hline & RWLS & -3.8 & -3.8 & 6.3 & yes & 6.2 & yes \\
\hline & EPR & -3.5 & -3.5 & 6.2 & yes & 6.2 & yes \\
\hline & AOR & -4.7 & -4.8 & 8.1 & no & 8.1 & no \\
\hline & JK & -4.0 & -4.0 & 6.7 & yes & 6.8 & yes \\
\hline & MDL LOW & -4.3 & -4.6 & 6.3 & yes & 6.6 & yes \\
\hline & MDL ZERO & -6.4 & -6.6 & 8.3 & no & 8.5 & no \\
\hline & LAD & -3.2 & -3.3 & 6.0 & yes & 6.1 & yes \\
\hline \multirow{10}{*}{ North Shore } & OLS & -11.1 & 5.0 & 20.4 & yes & 10.0 & yes \\
\hline & WLS & -9.3 & 5.6 & 20.7 & yes & 9.8 & yes \\
\hline & RLS & -11.0 & 5.0 & 20.4 & yes & 10.0 & yes \\
\hline & RWLS & -9.3 & 5.6 & 20.6 & yes & 9.8 & yes \\
\hline & EPR & -10.7 & 4.3 & 20.7 & yes & 10.0 & yes \\
\hline & AOR & -10.3 & 2.6 & 21.9 & yes & 11.6 & no \\
\hline & JK & -11.5 & 3.8 & 20.8 & yes & 10.4 & yes \\
\hline & MDL LOW & -2.5 & 6.8 & 24.0 & no & 10.2 & yes \\
\hline & MDL ZERO & 0.5 & 8.0 & 26.7 & no & 11.4 & no \\
\hline & LAD & -11.1 & 5.6 & 20.1 & yes & 9.6 & yes \\
\hline
\end{tabular}


Table 5. Hindcasts free of hardened structures.

\begin{tabular}{|c|c|c|c|c|c|c|c|}
\hline Region & Method & $\begin{array}{r}\text { Mean } \\
\text { all points }\end{array}$ & $\begin{array}{l}\text { EIP }(\mathrm{m}) \\
\text { w/o storms }\end{array}$ & $\begin{array}{c}\text { Mean }|\mathrm{EIP}|(\mathrm{m}) \\
\text { all points }\end{array}$ & $\begin{array}{l}\text { Statistically } \\
\text { Similar? }\end{array}$ & $\begin{array}{c}\text { Mean }|\mathrm{EIP}|(\mathrm{m}) \\
\text { w/o storms }\end{array}$ & $\begin{array}{l}\text { Statistically } \\
\text { Similar? }\end{array}$ \\
\hline \multirow{10}{*}{ Kihei } & OLS & 16.4 & 11.1 & 20.3 & yes & 16.4 & yes \\
\hline & WLS & 16.3 & 11.1 & 20.1 & yes & 16.4 & yes \\
\hline & RLS & 16.5 & 11.0 & 20.3 & yes & 16.4 & yes \\
\hline & RWLS & 16.3 & 11.0 & 21.1 & yes & 16.4 & yes \\
\hline & EPR & 9.8 & 11.3 & 18.1 & yes & 16.8 & yes \\
\hline & AOR & 8.5 & 9.4 & 27.6 & no & 17.0 & yes \\
\hline & JK & 17.4 & 9.4 & 21.0 & yes & 15.6 & yes \\
\hline & MDL LOW & 0.3 & 2.0 & 17.0 & yes & 15.2 & yes \\
\hline & MDL ZERO & -14.8 & -7.9 & 22.1 & yes & 17.6 & yes \\
\hline & LAD & 19.1 & 19.4 & 22.9 & yes & 21.9 & yes \\
\hline \multirow{10}{*}{ West Maui } & OLS & -7.9 & -6.7 & 13.4 & yes & 13.1 & yes \\
\hline & WLS & -8.0 & -6.7 & 13.4 & yes & 13.1 & yes \\
\hline & RLS & -7.7 & -7.1 & 13.2 & yes & 13.0 & yes \\
\hline & RWLS & -7.9 & -7.1 & 13.2 & yes & 13.0 & yes \\
\hline & EPR & -9.8 & -7.6 & 14.5 & yes & 12.9 & yes \\
\hline & AOR & -4.2 & -6.8 & 17.1 & yes & 14.0 & yes \\
\hline & JK & -7.7 & -6.0 & 13.2 & yes & 13.0 & yes \\
\hline & MDL LOW & -7.7 & -6.6 & 13.1 & yes & 13.1 & yes \\
\hline & MDL ZERO & -8.5 & -6.5 & 13.6 & yes & 13.2 & yes \\
\hline & LAD & -8.6 & -7.5 & 13.8 & yes & 13.0 & yes \\
\hline \multirow{10}{*}{ North Shore } & OLS & -3.7 & 2.3 & 13.3 & yes & 9.1 & yes \\
\hline & WLS & -3.6 & 2.3 & 13.2 & yes & 9.0 & yes \\
\hline & RLS & -3.6 & 2.3 & 13.4 & yes & 9.1 & yes \\
\hline & RWLS & -3.5 & 2.3 & 13.3 & yes & 9.0 & yes \\
\hline & EPR & -2.6 & 2.6 & 12.2 & yes & 8.9 & yes \\
\hline & AOR & -1.7 & 3.3 & 13.5 & yes & 9.3 & yes \\
\hline & $\mathrm{JK}$ & -3.8 & 2.2 & 13.5 & yes & 9.1 & yes \\
\hline & MDL LOW & -3.1 & 2.5 & 12.4 & yes & 8.0 & yes \\
\hline & MDL ZERO & -4.8 & 3.6 & 13.9 & no & 8.9 & yes \\
\hline & LAD & -3.7 & 2.2 & 13.1 & yes & 9.3 & yes \\
\hline
\end{tabular}


Table 6. Hindcasts with Hardened Structures.

\begin{tabular}{|c|c|c|c|c|c|c|c|}
\hline Region & Method & $\begin{array}{r}\text { Mean } \\
\text { all points } \\
\end{array}$ & $\begin{array}{l}\text { EIP }(\mathrm{m}) \\
\text { w/o storms }\end{array}$ & $\begin{array}{c}\text { Mean }|\mathrm{EIP}|(\mathrm{m}) \\
\text { all points }\end{array}$ & $\begin{array}{c}\text { Statistically } \\
\text { Similar? }\end{array}$ & $\begin{array}{c}\text { Mean }|\mathrm{EIP}|(\mathrm{m}) \\
\text { w/o storms }\end{array}$ & $\begin{array}{c}\text { Statistically } \\
\text { Similar? }\end{array}$ \\
\hline \multirow{10}{*}{ Kihei } & $\overline{\text { OLS }}$ & -2.7 & -1.5 & 11.9 & yes & 11.5 & yes \\
\hline & WLS & -2.8 & -1.5 & 11.9 & yes & 11.6 & yes \\
\hline & RLS & -1.7 & -1.5 & 11.9 & yes & 11.5 & yes \\
\hline & RWLS & -1.7 & -1.5 & 12.0 & yes & 11.6 & yes \\
\hline & EPR & -3.4 & -0.4 & 15.1 & yes & 12.9 & yes \\
\hline & AOR & -6.0 & -4.2 & 30.0 & no & 14.1 & yes \\
\hline & JK & -2.5 & -2.5 & 11.8 & yes & 10.6 & yes \\
\hline & MDL LOW & -6.9 & -2.4 & 13.3 & yes & 11.9 & yes \\
\hline & MDL ZERO & -9.9 & -4.2 & 16.8 & no & 15.5 & no \\
\hline & LAD & -2.2 & 0.7 & 12.5 & yes & 15.0 & no \\
\hline \multirow{10}{*}{ West Maui } & OLS & -5.0 & -5.7 & 9.0 & yes & 8.7 & yes \\
\hline & WLS & -6.1 & -6.2 & 8.7 & yes & 8.5 & yes \\
\hline & RLS & -4.6 & -5.1 & 8.7 & yes & 8.2 & yes \\
\hline & RWLS & -5.5 & -5.7 & 8.6 & yes & 8.0 & yes \\
\hline & EPR & -6.6 & -4.8 & 10.2 & yes & 10.0 & yes \\
\hline & AOR & -10.1 & -8.1 & 17.2 & no & 11.3 & yes \\
\hline & JK & -4.9 & -6.4 & 8.9 & yes & 8.3 & yes \\
\hline & MDL LOW & -3.5 & -4.8 & 9.6 & yes & 8.7 & yes \\
\hline & MDL ZERO & -4.0 & -4.8 & 10.8 & yes & 10.0 & yes \\
\hline & LAD & -6.2 & -4.5 & 9.6 & yes & 9.5 & yes \\
\hline \multirow{10}{*}{ North Shore } & OLS & -19.1 & -2.3 & 26.0 & yes & 31.2 & yes \\
\hline & WLS & -20.5 & -1.9 & 27.5 & yes & 31.0 & yes \\
\hline & RLS & -19.4 & -1.9 & 26.1 & yes & 30.8 & yes \\
\hline & RWLS & -20.7 & -1.6 & 27.6 & yes & 30.7 & yes \\
\hline & EPR & -14.5 & -0.4 & 24.5 & yes & 31.8 & yes \\
\hline & AOR & -12.8 & 4.7 & 27.5 & yes & 35.5 & yes \\
\hline & $\mathrm{JK}$ & -19.4 & 3.2 & 26.4 & yes & 33.0 & yes \\
\hline & MDL LOW & 1.4 & 7.0 & 41.5 & no & 35.2 & yes \\
\hline & MDL ZERO & 19.8 & 13.0 & 53.7 & no & 41.7 & no \\
\hline & LAD & -20.8 & -0.6 & 26.4 & yes & 29.7 & yes \\
\hline
\end{tabular}


Table 7. Kolmogorov-Smirnov (K-S) results of synthetic analysis. $\mathrm{H}=1$ : distributions are significantly different. $\mathrm{H}=0$ : distributions are not significantly different.

\begin{tabular}{|c|c|c|c|c|c|c|c|}
\hline \multirow{2}{*}{\multicolumn{2}{|c|}{ Comparison of }} & \multicolumn{2}{|c|}{$\begin{array}{c}\text { A } \\
\text { Without Storm Point }\end{array}$} & \multicolumn{2}{|c|}{$\begin{array}{cc}\mathrm{C} & \mathrm{D} \\
\text { Storm - middle position }\end{array}$} & \multicolumn{2}{|c|}{$\begin{array}{l}\mathrm{E} \\
\text { Storm - end position }\end{array}$} \\
\hline & & Less Noise & More Noise & Less Noise & More Noise & Less Noise & More Noise \\
\hline Method 1 & Method 2 & $\mathrm{H}$ & & & & & H \\
\hline OLS & WLS & 1 & 0 & 0 & 0 & 0 & 0 \\
\hline OLS & RLS & 0 & 0 & 0 & 0 & 1 & 0 \\
\hline OLS & RWLS & 1 & 0 & 0 & 0 & 1 & 0 \\
\hline OLS & JK & 0 & 0 & 0 & 0 & 0 & 0 \\
\hline OLS & EPR & 0 & 0 & 0 & 1 & 1 & 1 \\
\hline OLS & LAD & 0 & 0 & 0 & 1 & 1 & 0 \\
\hline OLS & WLAD & 1 & 0 & 0 & 0 & 1 & 0 \\
\hline OLS & AOR & 1 & 1 & 1 & 1 & 1 & 1 \\
\hline OLS & MDL ZERO & 1 & 1 & 1 & 1 & 1 & 1 \\
\hline OLS & MDL LOW & 1 & 1 & 1 & 1 & 1 & 1 \\
\hline WLS & RLS & 1 & 0 & 0 & 0 & 1 & 0 \\
\hline WLS & RWLS & 0 & 0 & 1 & 0 & 1 & 0 \\
\hline WLS & $\mathrm{JK}$ & 1 & 0 & 0 & 0 & 0 & 0 \\
\hline WLS & EPR & 1 & 1 & 0 & 1 & 1 & 1 \\
\hline WLS & LAD & 1 & 1 & 0 & 1 & 1 & 0 \\
\hline WLS & WLAD & 0 & 1 & 1 & 0 & 1 & 0 \\
\hline WLS & $\mathrm{AOR}$ & 1 & 1 & 1 & 1 & 1 & 1 \\
\hline WLS & MDL ZERO & 1 & 1 & 1 & 1 & 1 & 1 \\
\hline WLS & MDL LOW & 1 & 1 & 1 & 1 & 1 & 1 \\
\hline RLS & RWLS & 1 & 0 & 0 & 0 & 0 & 0 \\
\hline RLS & JK & 0 & 0 & 0 & 0 & 1 & 0 \\
\hline RLS & EPR & 1 & 0 & 0 & 1 & 1 & 1 \\
\hline RLS & LAD & 0 & 0 & 0 & 1 & 0 & 0 \\
\hline RLS & WLAD & 0 & 0 & 0 & 0 & 0 & 0 \\
\hline RLS & AOR & 1 & 1 & 1 & 1 & 1 & 1 \\
\hline RLS & MDL ZERO & 1 & 1 & 1 & 1 & 1 & 1 \\
\hline RLS & MDL LOW & 1 & 1 & 1 & 1 & 1 & 1 \\
\hline RWLS & $J K$ & 1 & 0 & 0 & 0 & 1 & 0 \\
\hline RWLS & EPR & 1 & 1 & 1 & 1 & 1 & 1 \\
\hline RWLS & LAD & 1 & 1 & 1 & 1 & 0 & 0 \\
\hline RWLS & WLAD & 0 & 1 & 0 & 0 & 0 & 0 \\
\hline RWLS & AOR & 1 & 1 & 1 & 1 & 1 & 1 \\
\hline RWLS & MDL ZERO & 1 & 1 & 1 & 1 & 1 & 1 \\
\hline RWLS & MDL LOW & 1 & 1 & 1 & 1 & 1 & 1 \\
\hline JK & EPR & 0 & 0 & 0 & 1 & 1 & 1 \\
\hline JK & LAD & 0 & 1 & 0 & 1 & 1 & 0 \\
\hline $\mathrm{JK}$ & WLAD & 0 & 0 & 0 & 0 & 1 & 0 \\
\hline JK & AOR & 1 & 1 & 1 & 1 & 1 & 1 \\
\hline JK & MDL ZERO & 1 & 1 & 1 & 1 & 1 & 1 \\
\hline$J \mathrm{~K}$ & MDL LOW & 1 & 1 & 1 & 1 & 1 & 1 \\
\hline EPR & LAD & 0 & 0 & 0 & 0 & 1 & 1 \\
\hline EPR & WLAD & 1 & 0 & 1 & 0 & 1 & 1 \\
\hline EPR & AOR & 1 & 1 & 1 & 1 & 1 & 1 \\
\hline EPR & MDL ZERO & 1 & 1 & 1 & 1 & 1 & 1 \\
\hline EPR & MDL LOW & 1 & 1 & 1 & 1 & 1 & 1 \\
\hline LAD & WLAD & 1 & 0 & 1 & 0 & 0 & 0 \\
\hline LAD & AOR & 1 & 1 & 1 & 1 & 1 & 1 \\
\hline LAD & MDL ZERO & 1 & 1 & 1 & 1 & 1 & 1 \\
\hline LAD & MDL LOW & 1 & 1 & 1 & 1 & 1 & 1 \\
\hline WLAD & AOR & 1 & 1 & 1 & 1 & 1 & 1 \\
\hline WLAD & MDL ZERO & 1 & 1 & 1 & 1 & 1 & 1 \\
\hline WLAD & MDL LOW & 1 & 1 & 1 & 1 & 1 & 1 \\
\hline AOR & MDL ZERO & 1 & 1 & 1 & 1 & 1 & 1 \\
\hline $\mathrm{AOR}$ & MDL LOW & 1 & 1 & 1 & 1 & 1 & 1 \\
\hline MDL ZERO & MDL LOW & 1 & 1 & 1 & 1 & 0 & 1 \\
\hline
\end{tabular}


Table 8. Binning Trends.

\begin{tabular}{|c|c|c|c|c|c|}
\hline Region & Beach & Wave Climate of Region & Offshore Bottom & Comments & Overall Bin trends \\
\hline \multirow[t]{2}{*}{ Kihei } & \begin{tabular}{|} 
Southern Beaches \\
Big Beach \\
Little Beach \\
Maluaka \\
Onuoli
\end{tabular} & $\begin{array}{c}\text { south swell, refracted north } \\
\text { swell and tradewind waves } \\
\text { no fringing reef }\end{array}$ & No fringing reef & & $\begin{array}{l}\text { northern portions of a beach } \\
\text { are distinct from southern } \\
\text { portions. }\end{array}$ \\
\hline & $\begin{array}{c}\text { Central Beaches } \\
\text { Kam 1 } \\
\text { Kam } 2 \\
\text { Kam 3 } \\
\text { Ulua }\end{array}$ & $\begin{array}{l}\text { minimal south swell and } \\
\text { refracted north swell } \\
\text { occasional kona storm waves }\end{array}$ & $\begin{array}{l}\text { No fringing reef } \\
\text { sandy bottom }\end{array}$ & seawall & uniformity within beaches \\
\hline West Maui & \begin{tabular}{|c|} 
Kaanapali \\
North Kaanapali \\
Keonenui \\
Kapalua \\
\end{tabular} & $\begin{array}{l}\text { north pacific swell, south } \\
\text { swell and kona storm waves }\end{array}$ & $\begin{array}{l}\text { portions have fringing reefs } \\
\text { rocky and sandy bottoms }\end{array}$ & seawall & $\begin{array}{l}\text { erosion on one end of the } \\
\text { beach and accretion on the } \\
\text { other end of the beach. }\end{array}$ \\
\hline North Shore & $\begin{array}{c}\text { Kaehu } \\
\text { Kanaha } \\
\text { Sprecklesville }\end{array}$ & $\begin{array}{c}\text { north pacific swell and } \\
\text { tradewind waves }\end{array}$ & fringing reefs & $\begin{array}{l}5 \text { groins throughout beach } \\
\text { offshore rock platform, revetment }\end{array}$ & $\begin{array}{l}\text { eastern and western sections } \\
\text { of the beach are distinct }\end{array}$ \\
\hline
\end{tabular}


Table 9. Forecasts at Kanaha (North Shore). Removing the 1960 tsunami position does not improve the prediction.

\begin{tabular}{|ccc|}
\hline \hline & \multicolumn{2}{c|}{ Mean $|\mathrm{EIP}|(\mathrm{m})$} \\
Method & all points & w/o storms \\
\hline OLS & 11.3 & 12.9 \\
WLS & 11.4 & 12.8 \\
RLS & 11.2 & 12.9 \\
RWLS & 11.4 & 12.8 \\
EPR & 11.4 & 13.0 \\
AOR & 11.5 & 13.1 \\
JK & 11.3 & 12.9 \\
MDL LOW & 11.3 & 12.5 \\
MDL ZERO & 11.3 & 12.5 \\
LAD & 11.3 & 13.1 \\
\hline
\end{tabular}


Table 10. Forecasts at Kahului (North Shore) after removing predictions made using data from $\mathrm{T}$-sheet and the 1960 shorelines.

\begin{tabular}{|ccc|}
\hline & \multicolumn{2}{c|}{ Mean $|\mathrm{EIP}|(\mathrm{m})$} \\
Method & all points & w/o storms \\
\hline OLS & 8.9 & 9.2 \\
WLS & 10.1 & 9.1 \\
RLS & 9.0 & 9.2 \\
RWLS & 10.1 & 9.1 \\
EPR & 9.2 & 9.2 \\
AOR & 11.0 & 11.4 \\
JK & 8.9 & 9.8 \\
MDL LOW & 21.6 & 9.5 \\
MDL ZERO & 28.8 & 10.8 \\
LAD & 10.2 & 8.7 \\
\hline
\end{tabular}


Table 11. Hindcast uncertainties of the known position and the predicted positions with all points and without storm data.

$\left.\begin{array}{|cccccc|}\hline \hline & & & \begin{array}{c}\text { Known } \\ \text { Position }\end{array} & \begin{array}{c}\text { 95\% C.I. } \\ \text { all points } \\ \text { Average predicted }\end{array} & \begin{array}{c}\text { 95\% C.I. } \\ \text { w/o storm } \\ \text { Average predicted }\end{array} \\ & \text { Area } & \text { Year } & \begin{array}{c}\text { Uncertainty (m) } \\ \text { Position uncertainty (m) }\end{array} \\ \text { Position uncertainty (m) }\end{array}\right)$




\section{APPENDIX B: FIGURES}

Figure 1. Published shoreline change rate methods applied to one data set of 7 shoreline positions. A positive slope shows erosion, while a negative slope shows accretion. The shoreline positions are signified as crosses and the diamonds represent outliers.

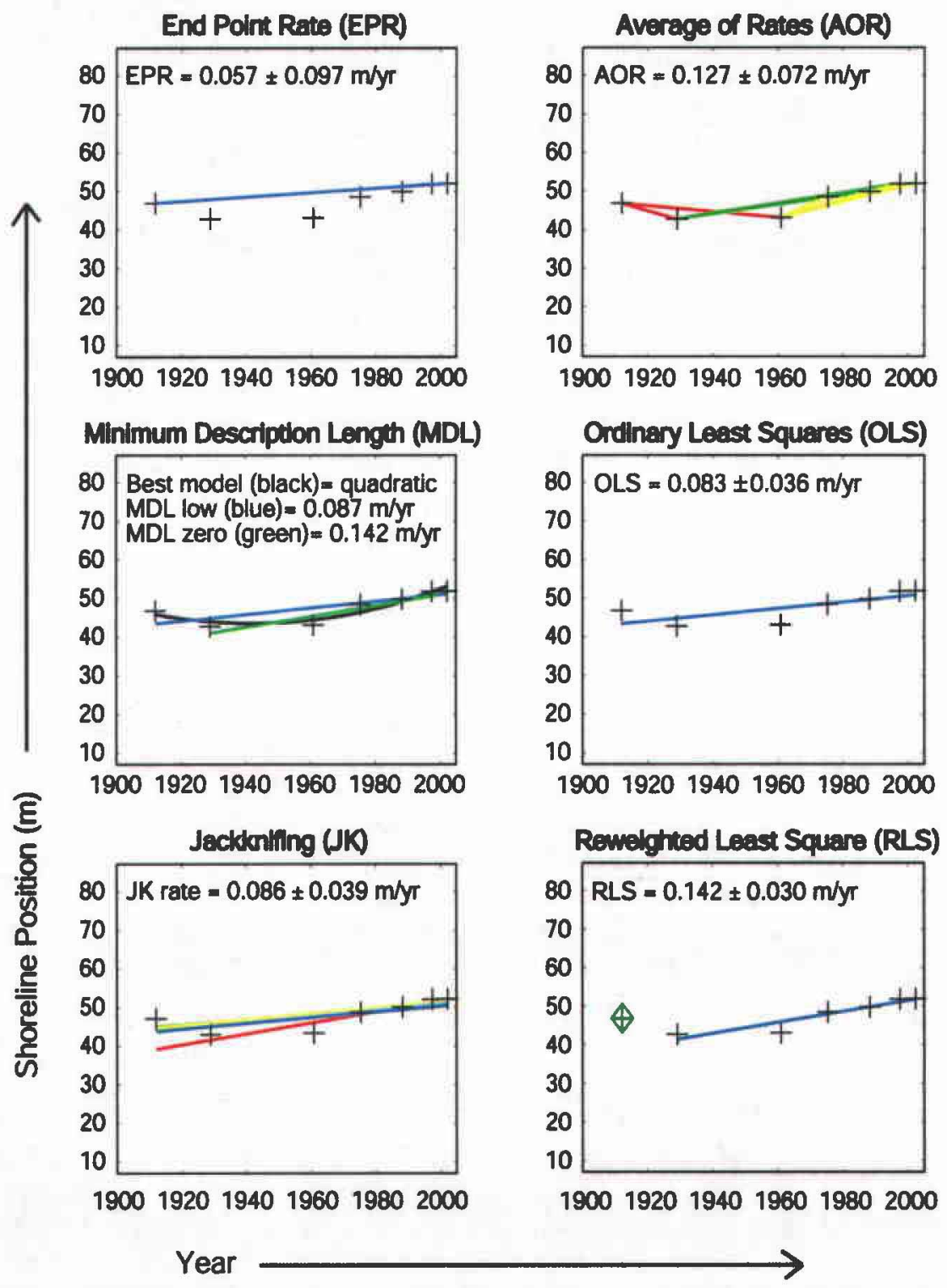


Figure 2. New shoreline change rate methods. The crosses represent shoreline position. The vertical lines are 1- $\sigma$ error bars associated with each shoreline position and the diamonds correspond to outliers.

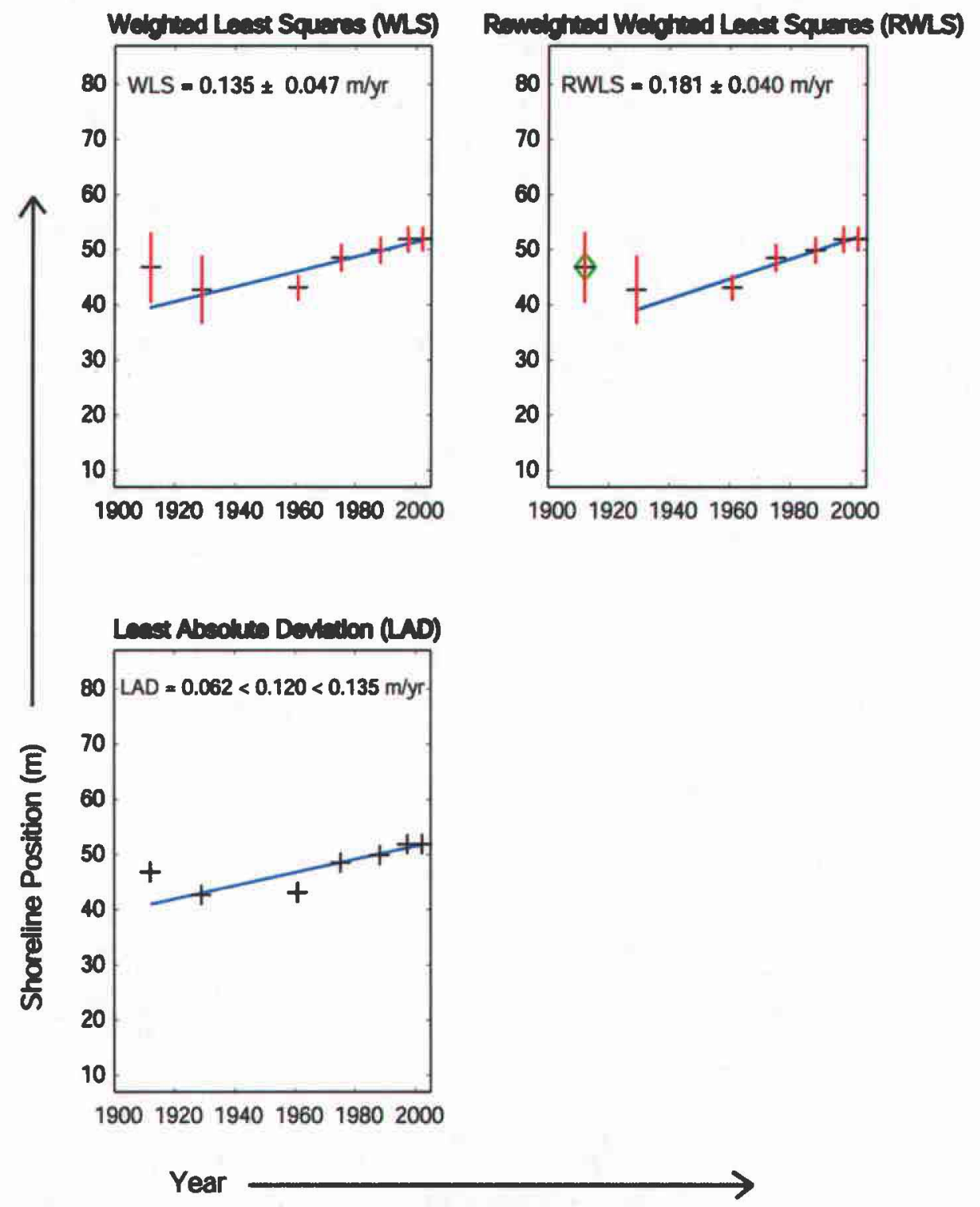


Figure 3. Three classified regions within Maui that experience different weather conditions and wave dynamics.

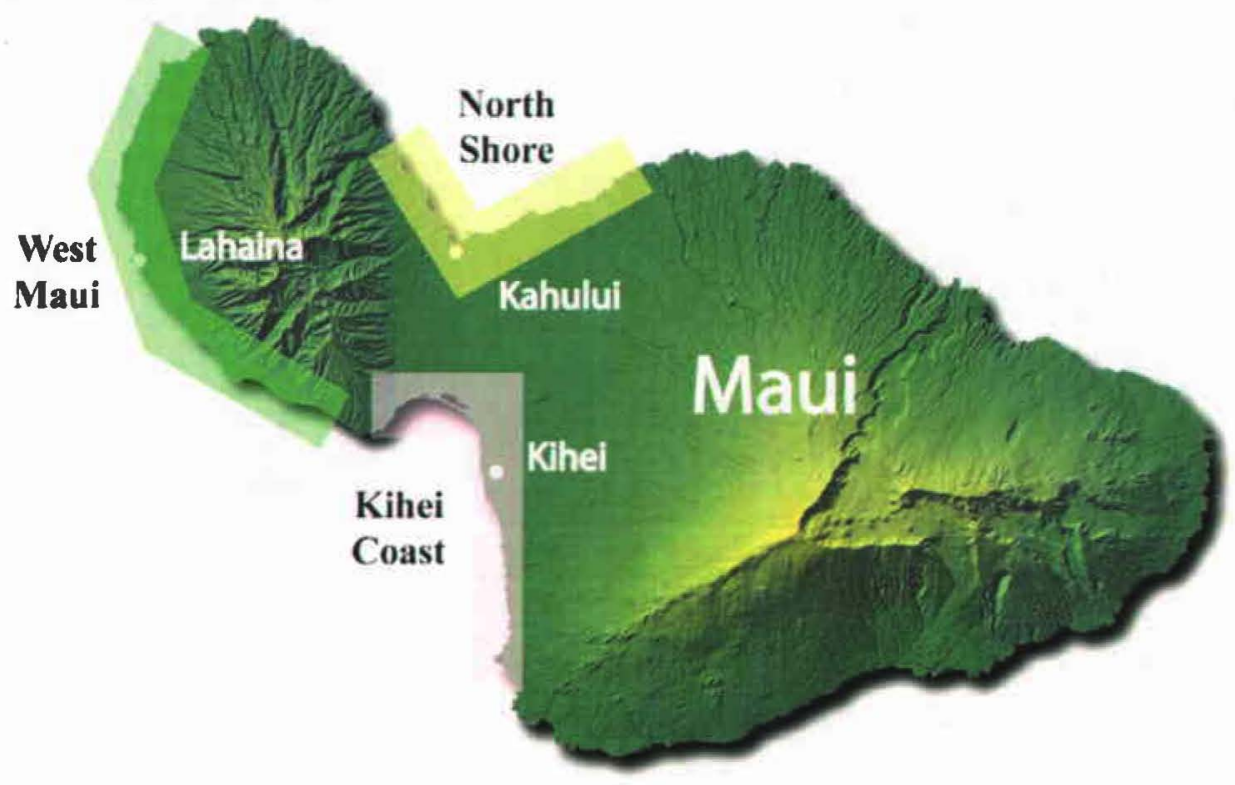


Figure 4. Top - Shore normal transects are spaced $20 \mathrm{~m}$ alongshore. In this example, transect window length is 4 . The erosion rate of the first four adjacent transects (1) is compared to the rate of all the other transects in this beach. Next, the erosion rate of the next four transects (2) is compared to the rate of all other transects. This continues throughout the beach $(3 \& 4)$ until the rate of the last four transects is compared to the rest of the beach. The window spacing then increases to $6,8,10$, etc. transects. Bottom Another visualization of transect binning at a window size of 4 . The numbers 1,2, and 3 correspond to the numbers in the figure above. $R_{1}$ is the binned erosion rate of 4 transects. $R_{2}$ is the binned erosion rate of the rest of the beach. A t-pooled test examines whether $R_{1}$ is significantly different from $R_{2}$.
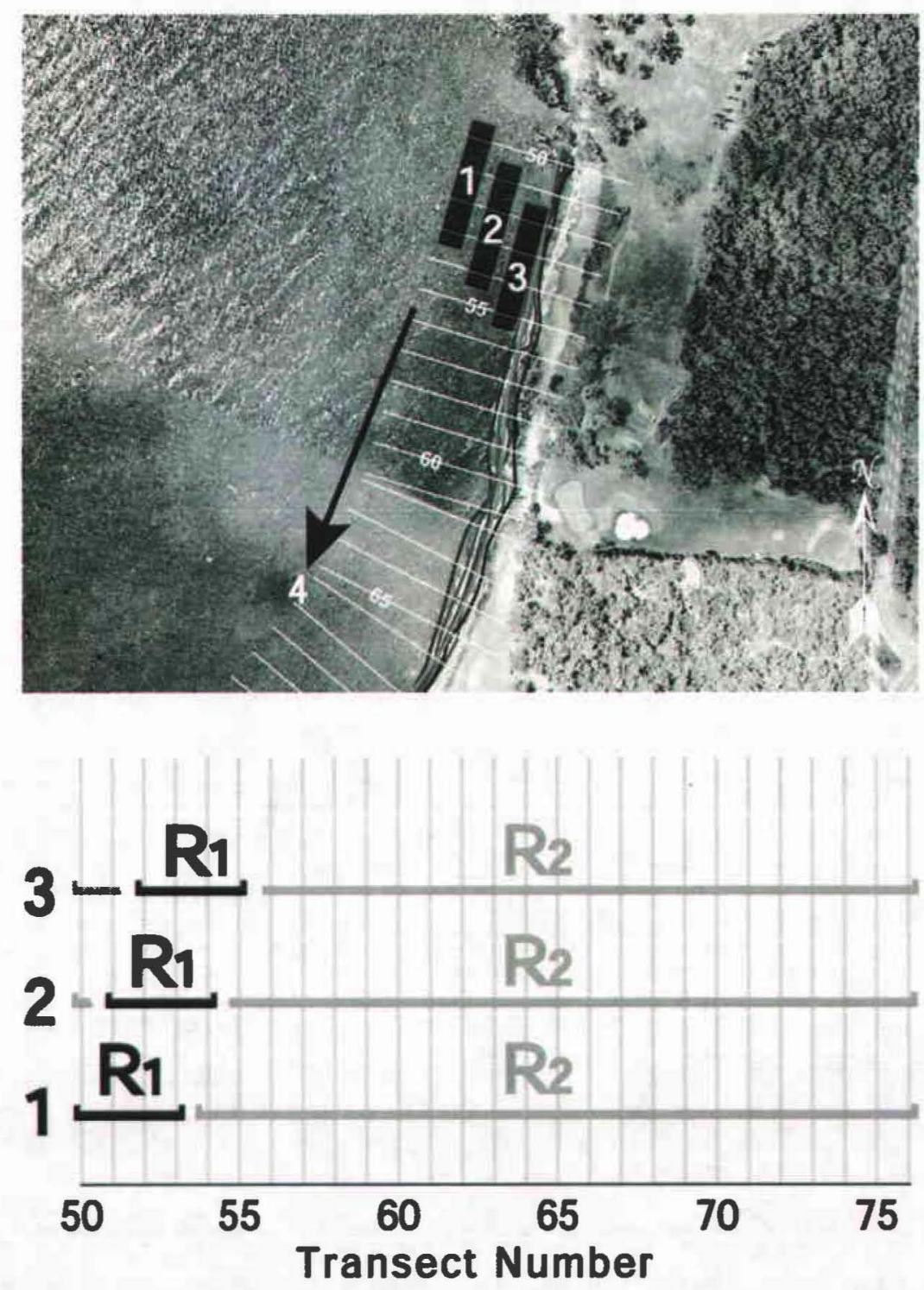
Figure 5. Vertical lines represent transects. Y-axis is the window size of the transect grouping. The first window size is 4 , meaning 4 adjacent transects are grouped for each rate calculation. Horizontal lines represent groups of transects whose rates did not agree with the binned rates of all other transects (t-test). A t-test is calculated for any overlapping transects within a window size (represented by boxes).

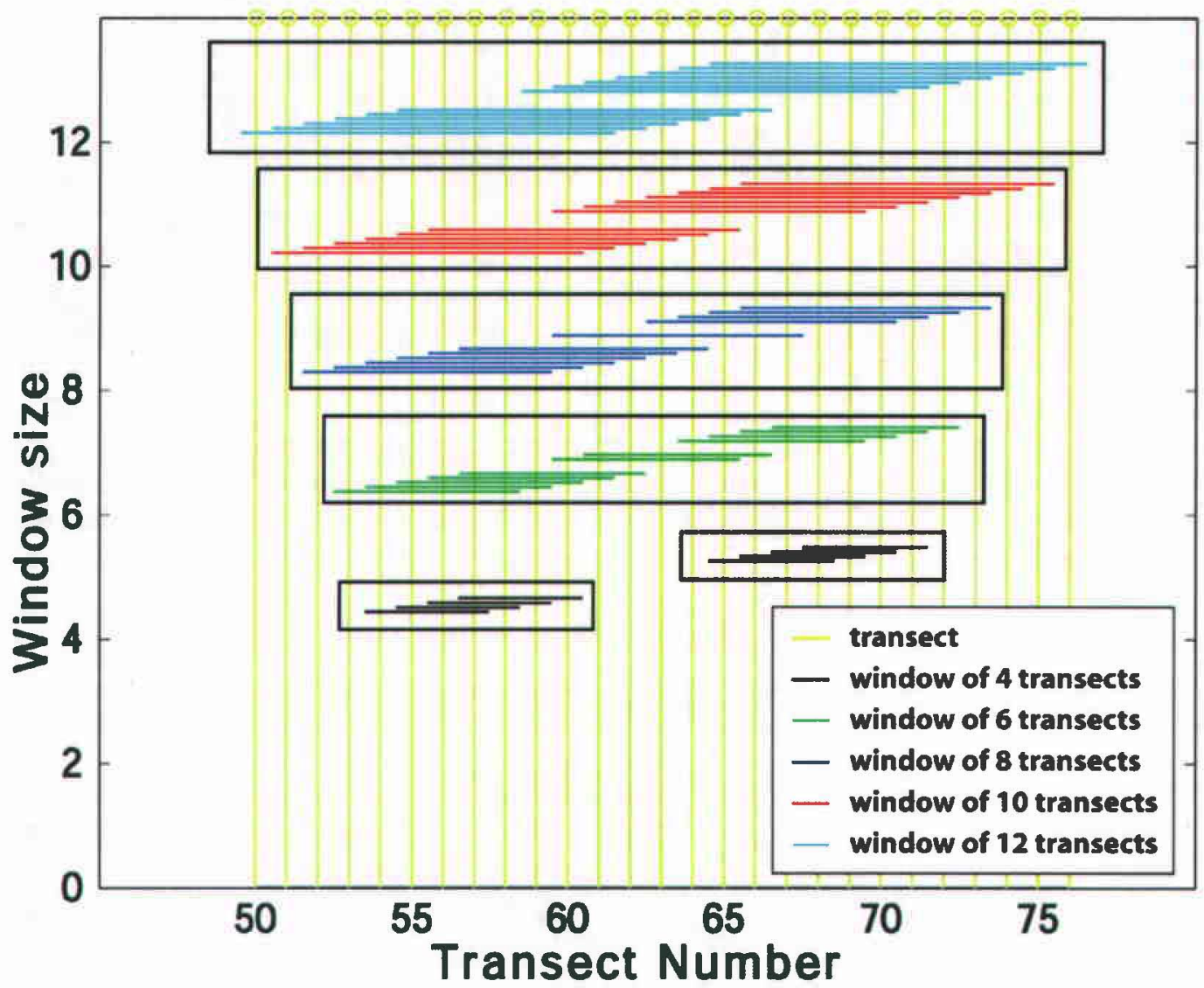


Figure 6. T-test results within each window size. At window size 4, the overlapping transects are not significantly different from each other (A). At window size 6, two groups were identified that were significantly different from each other (B).

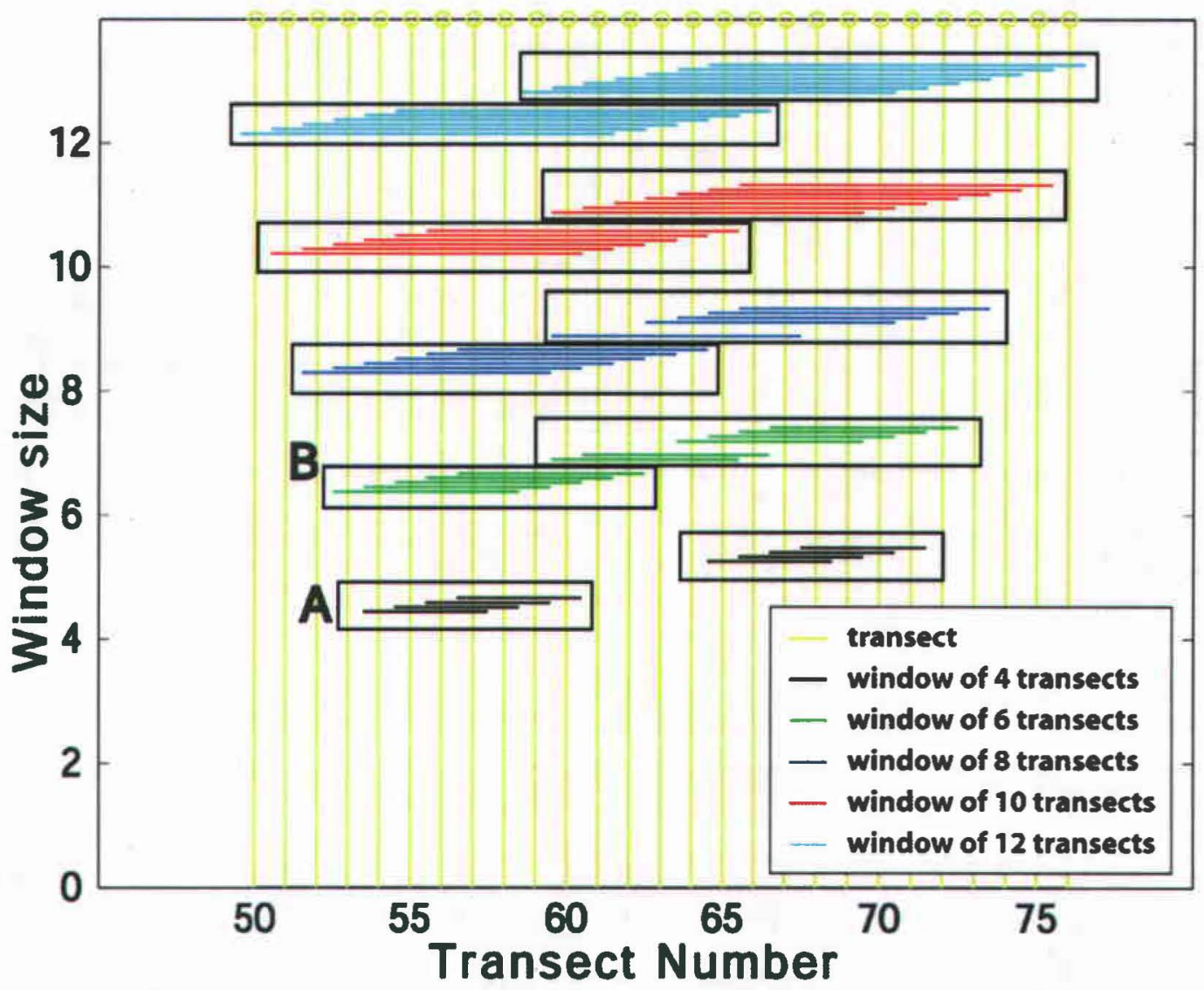


Figure 7. Clusters of transects (or cells) are identified based on t-tests of all windows with common transects. For this beach, there are two distinct clusters (labeled 1 \& 2). One side of the beach has significantly different long-term rates compared to the other side of the beach. Transects that are shared by both clusters are considered transitional zones.

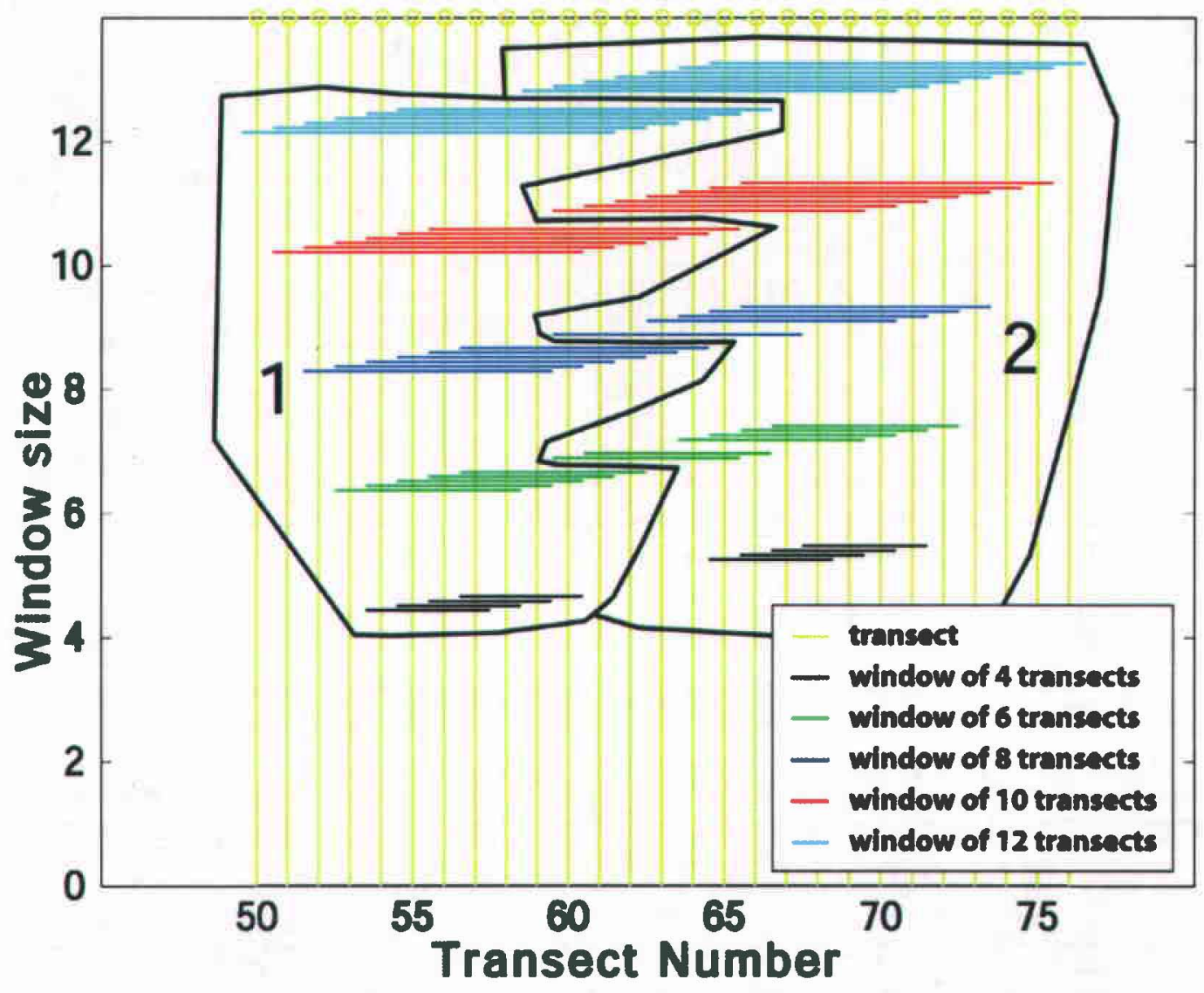


Figure 8. Each cluster is assigned a color and each transect within a cluster is given a shade of that color. Transect shade corresponds to the frequency of windows that intersect the transect. Transects with a higher frequency of windows will be darker than transects with a lower frequency of windows. Groups $\mathrm{A}$ and $\mathrm{C}$ represent two distinct clusters. Group B represents the overlap between Groups A and C.

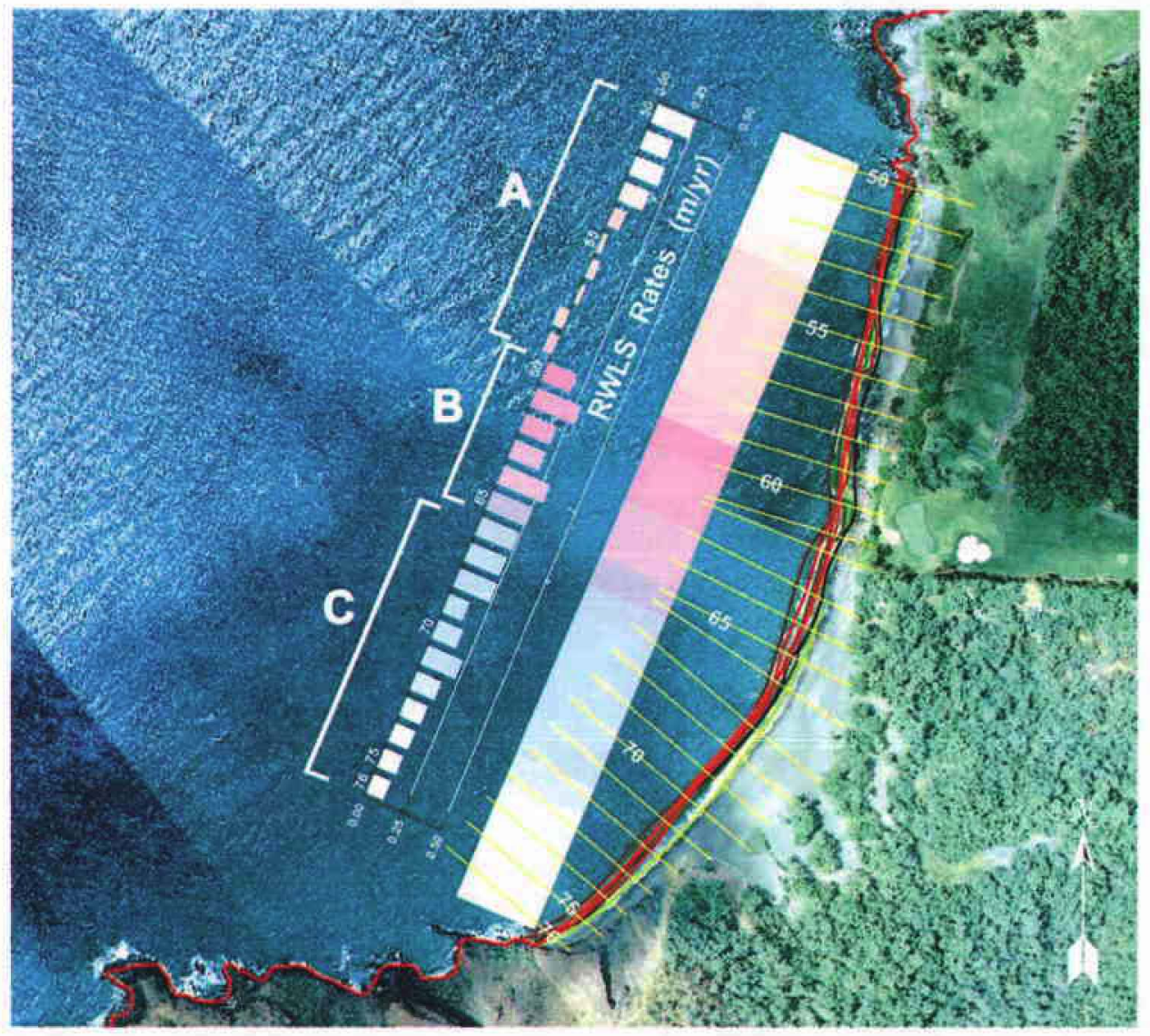


Figure 9. Predictions from a transect in Kahului. Predictions were made using the Tsheets and 1960 aerial photograph positions. Although a tsunami affected the area 5 months before the 1960 photograph, accretion is predicted. Erosion at the rate of $3 \mathrm{~m} / \mathrm{yr}$ occurred between 1960 and the next position (1975).

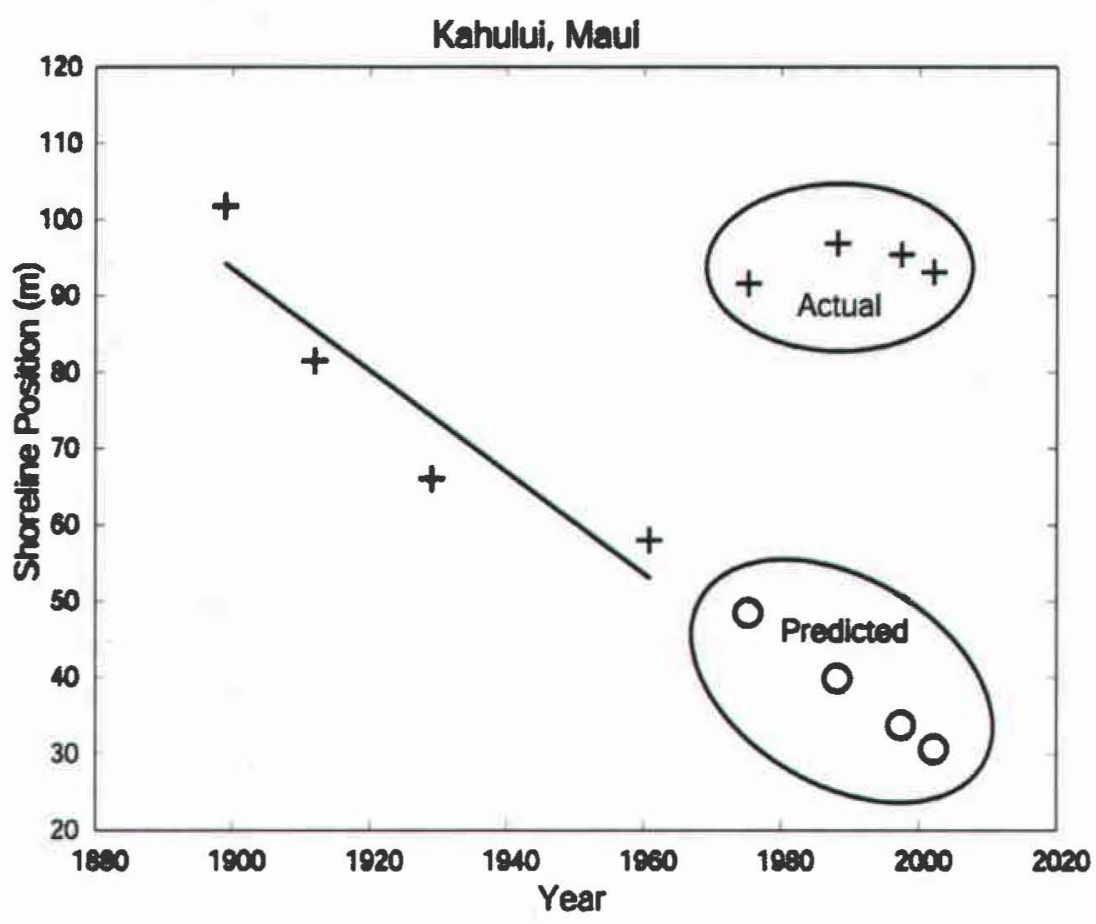


Figure 10. Histogram of 1000 rates calculated from synthetic beach time series with low noise. The diamond depicts the true erosion rate at $0.1 \mathrm{~m} / \mathrm{yr}$.

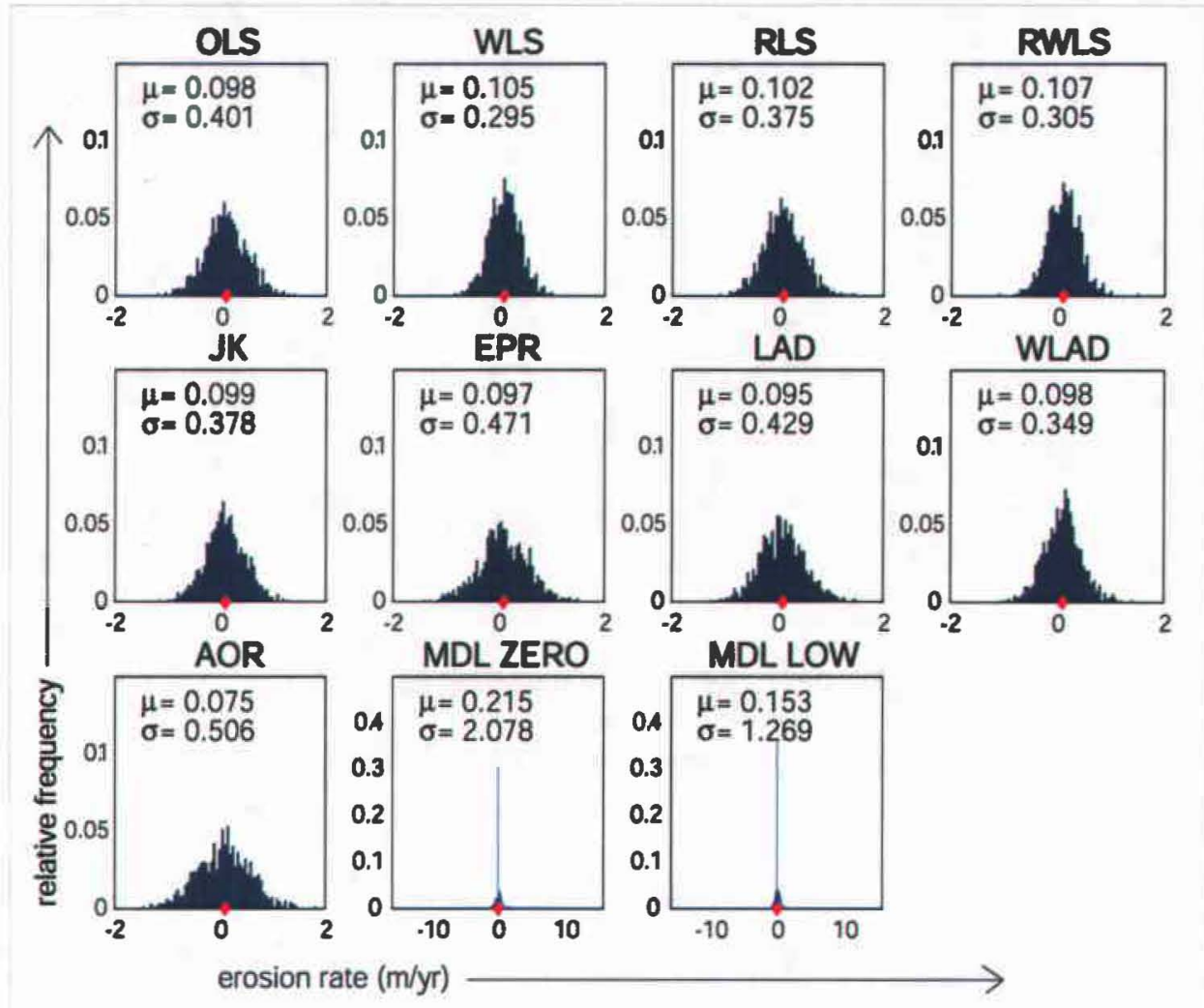


Figure 11. Histogram of 1000 rates calculated from synthetic beach time series with high noise. The diamond depicts the true erosion rate at $0.1 \mathrm{~m} / \mathrm{yr}$.

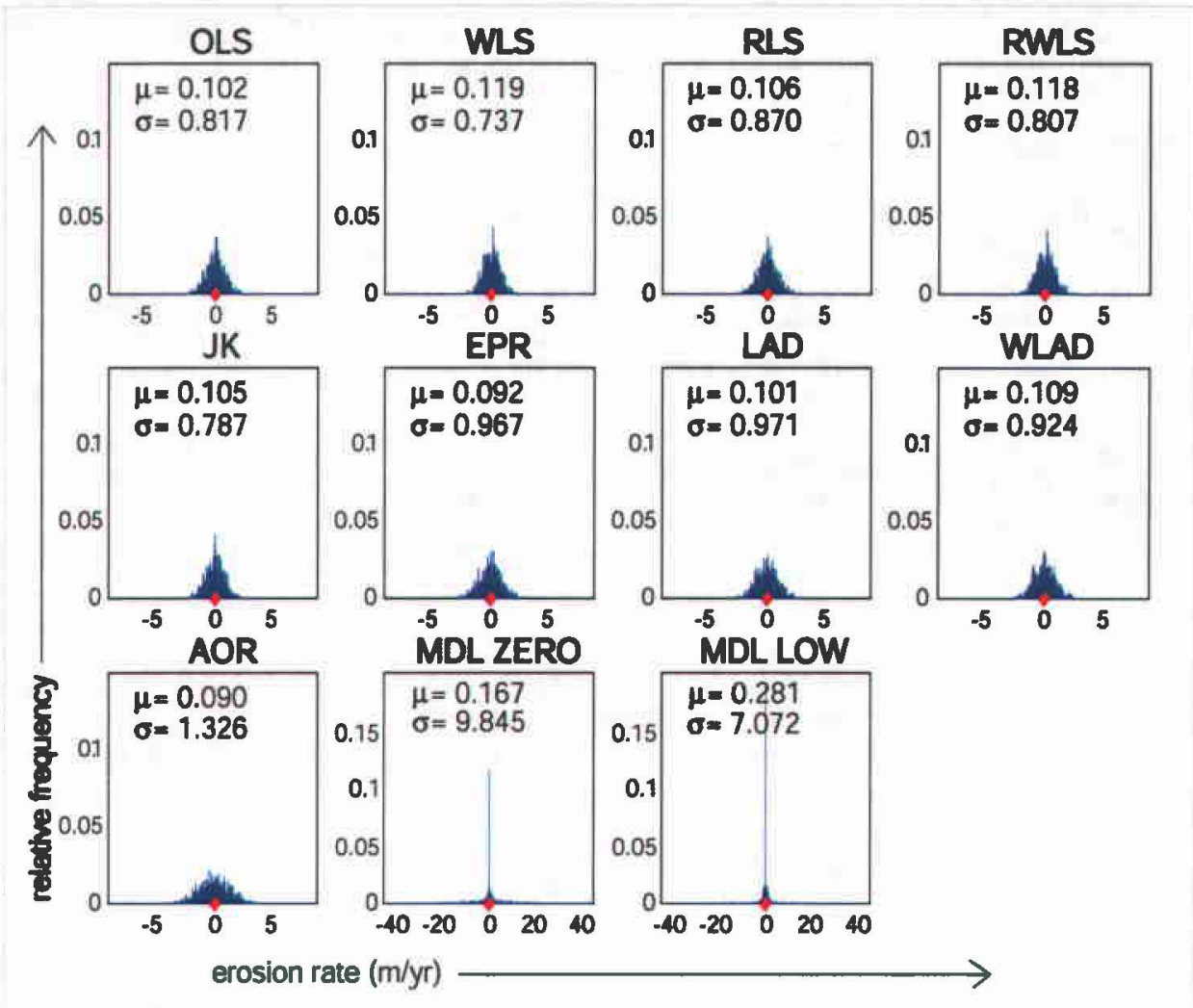


Figure 12. Histogram of 1000 rates calculated from synthetic beach time series with a storm at a middle point and with low noise. The diamond depicts the true erosion rate at $0.1 \mathrm{~m} / \mathrm{yr}$.

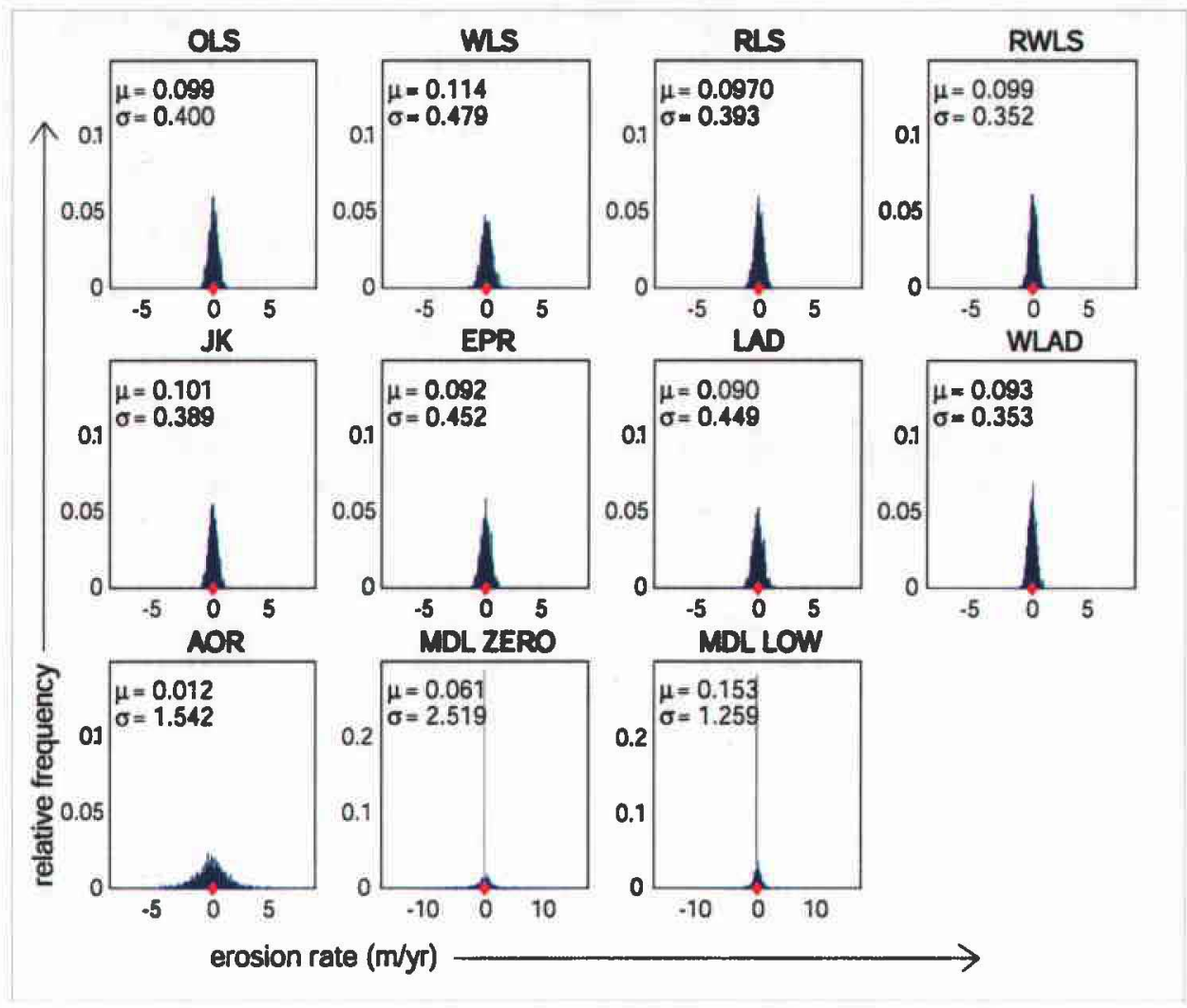


Figure 13. Histogram of 1000 rates calculated from synthetic beach time series with a storm at a middle point and with high noise. The diamond depicts the true erosion rate at $0.1 \mathrm{~m} / \mathrm{yr}$.

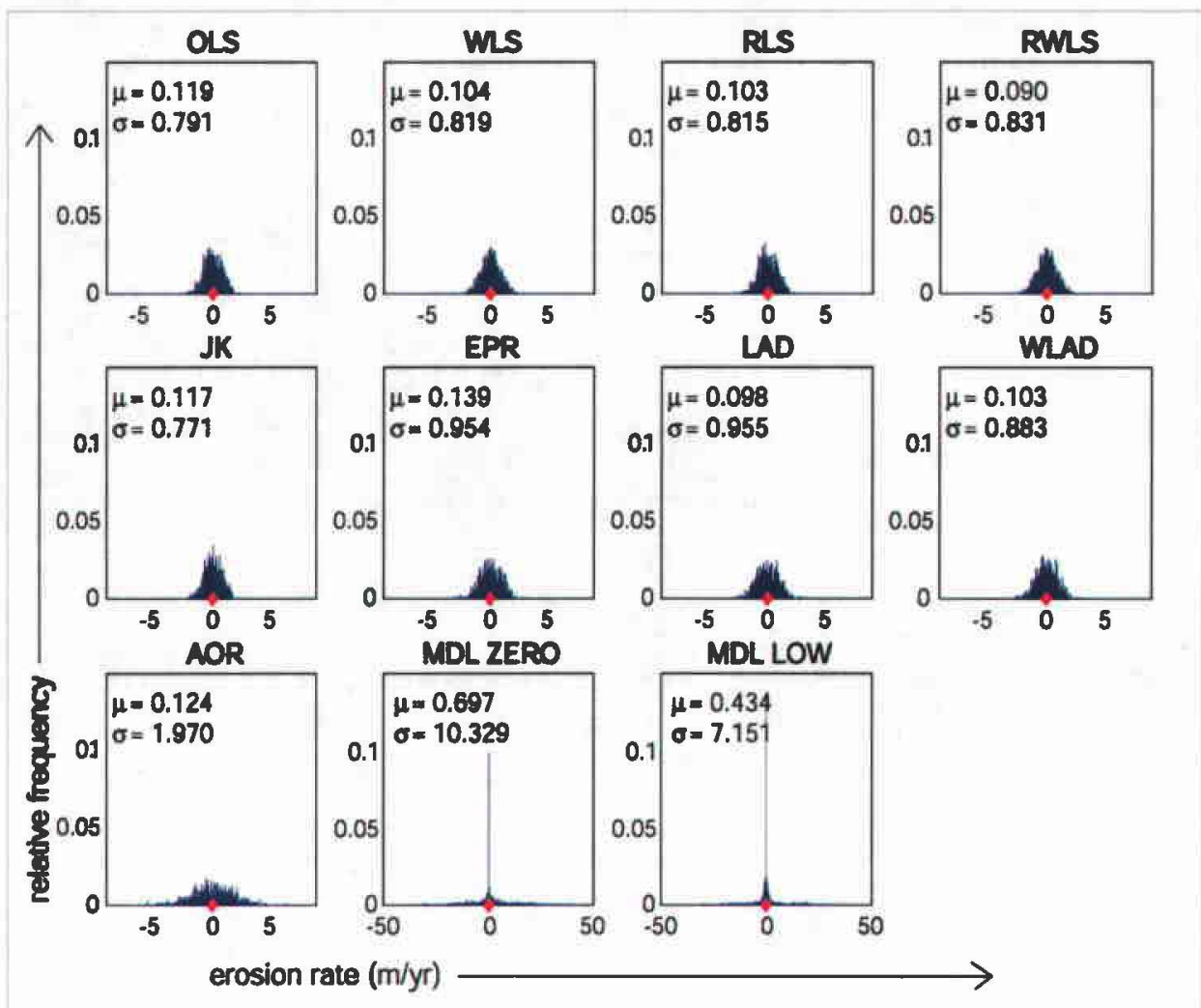


Figure 14. Histogram of 1000 rates calculated from synthetic beach time series with a storm at the end point and with low noise. The diamond depicts the true erosion rate at $0.1 \mathrm{~m} / \mathrm{yr}$.

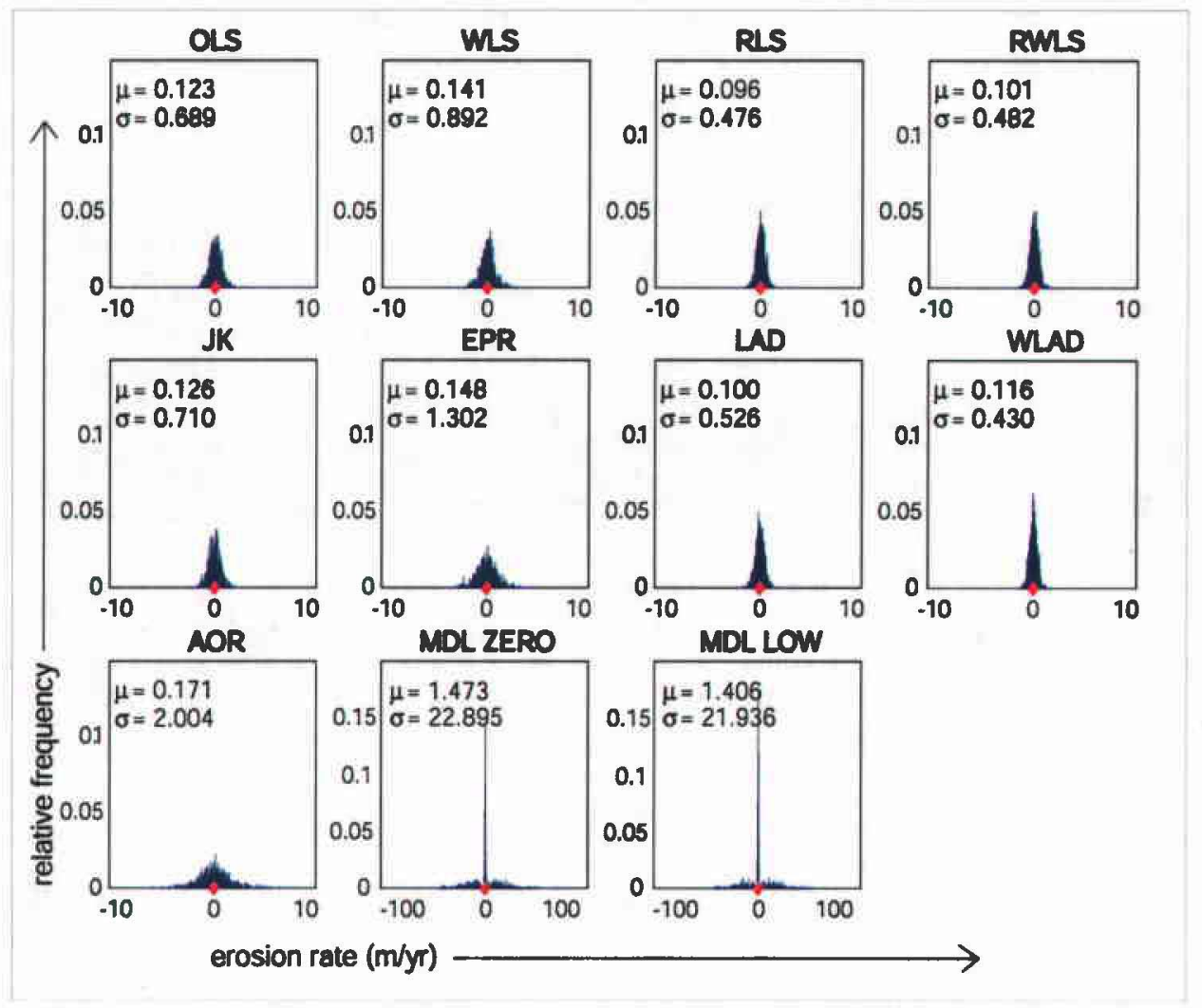


Figure 15. Histogram of 1000 rates calculated from synthetic beach time series with a storm at the end point and with high noise. The diamond depicts the true erosion rate at $0.1 \mathrm{~m} / \mathrm{yr}$.

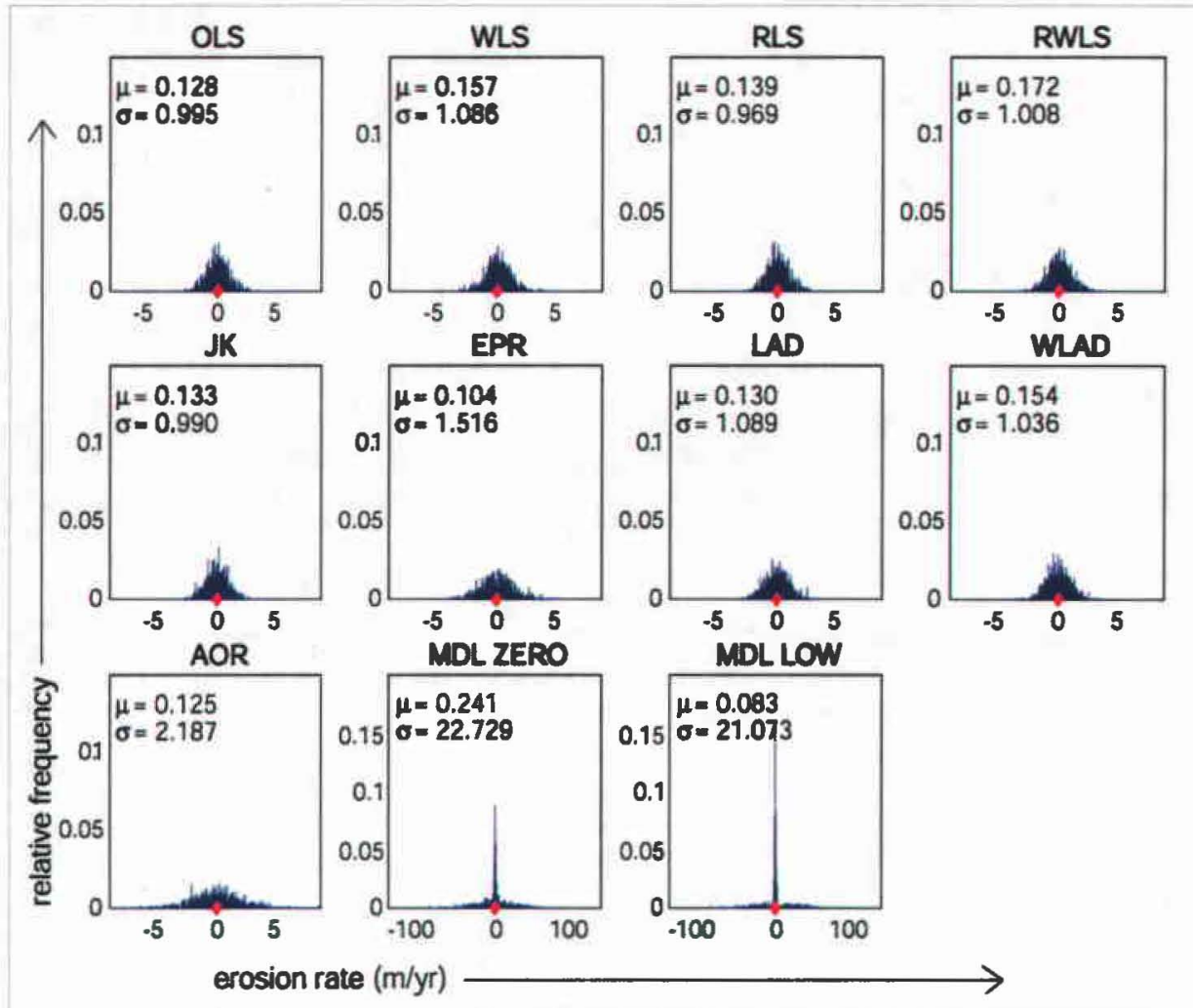


Figure 16. Kaanapali, Maui. Results from binning. Eversole and Fletcher (2003) identify transect \#105 as an inflection point.

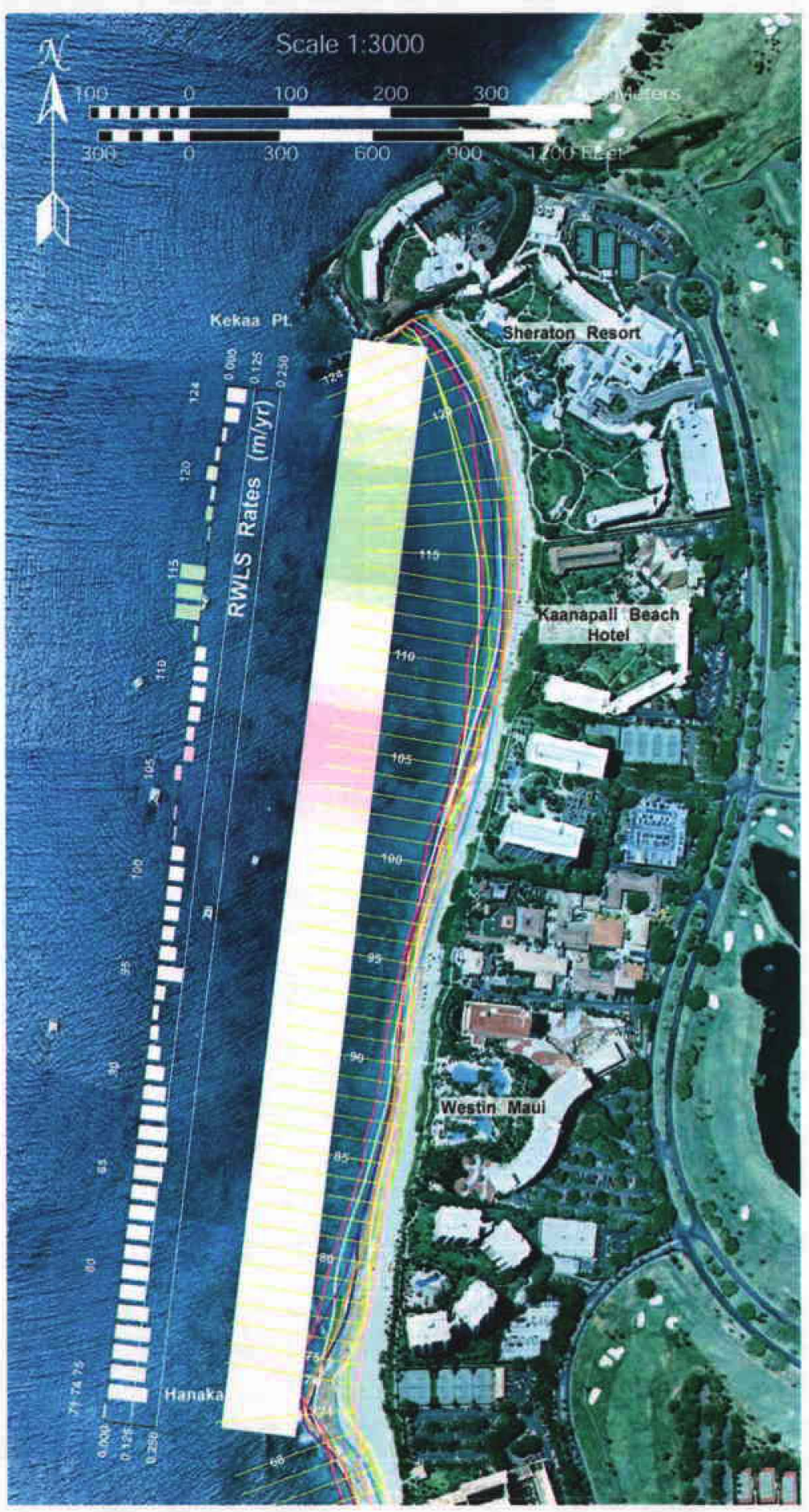


Figure 17. Flow chart showing steps in creating a hazard map. Methods appropriate for Hawai' $i$ are highlighted in gray. We choose RWLS over WLAD due to the simplicity of RWLS.

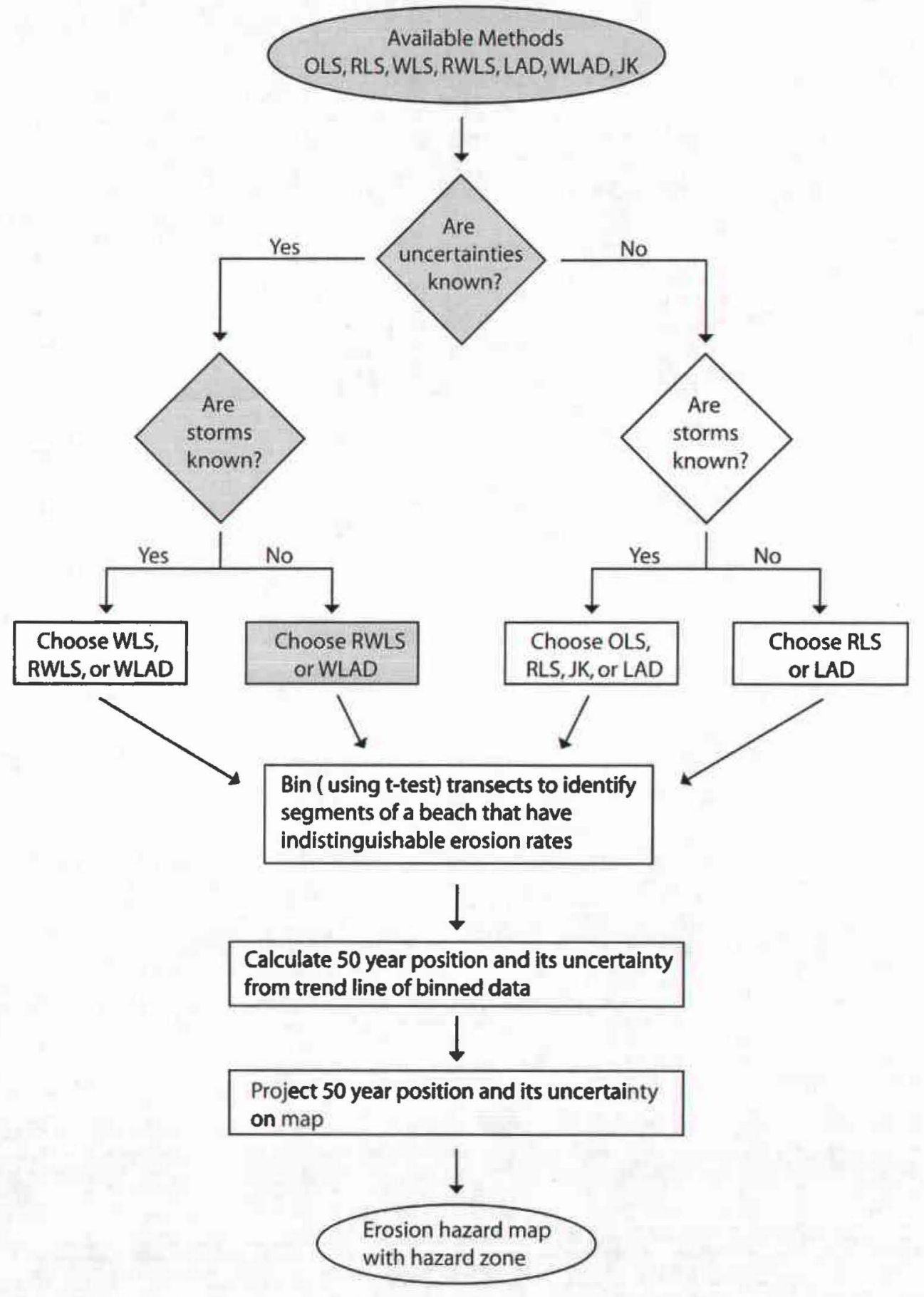


Figure 18. An example of an Erosion Hazard Map. The setback (red line) is surrounded by $1-\sigma$ confidence bands (blue lines). The hazard zone is highlighted in yellow.

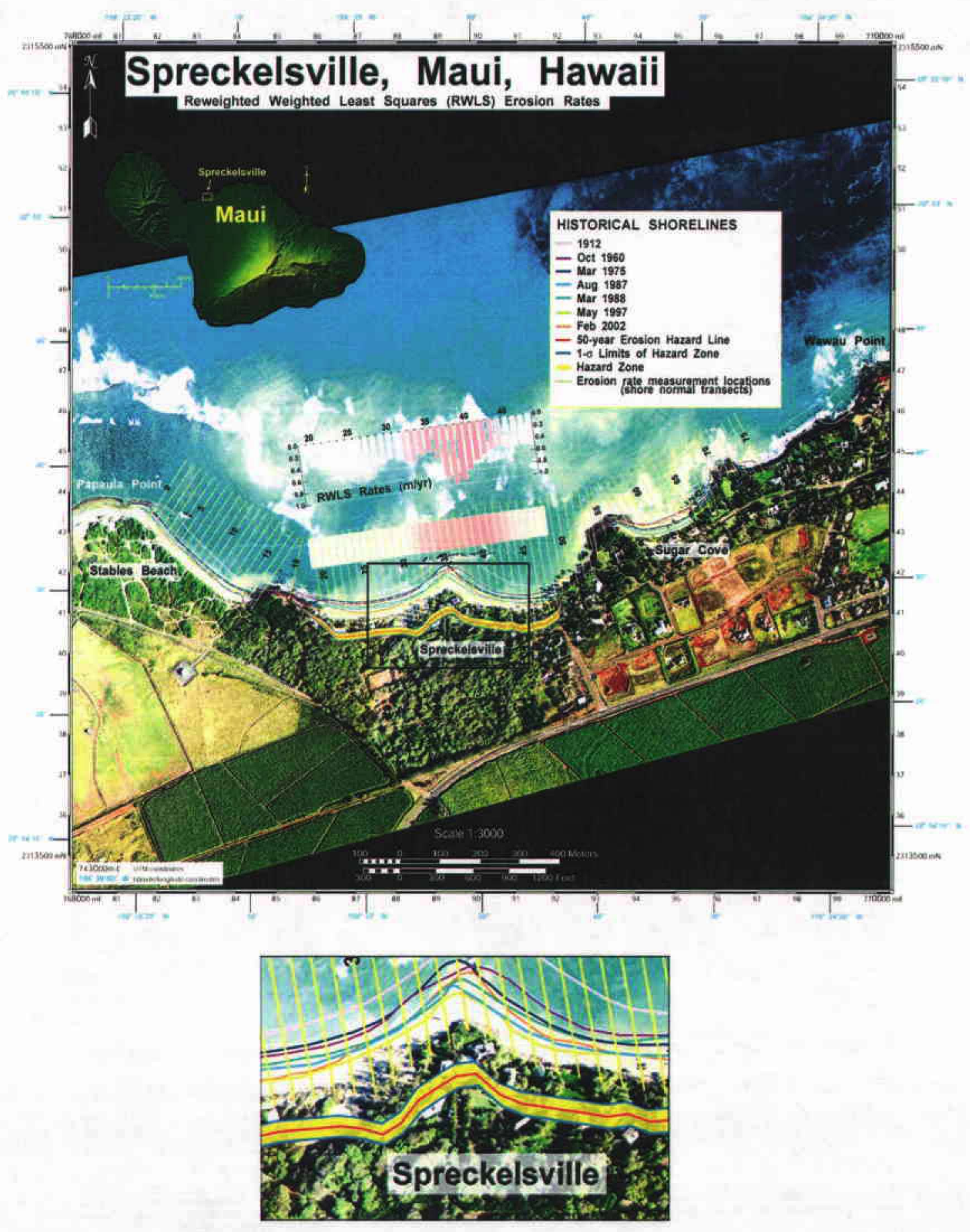




\section{APPENDIX C: ERRORS AND UNCERTAINTIES}

To calculate erosion rates on beaches in Hawaii, we use the beach toe as our shoreline position, which is digitized from images of varying years. The beach toe is typically coincident with the position of lower low waterline. The high contrast of beaches in Hawaii make it difficult to identify the MHWL in aerial photographs, hence, beach toe is used as the shoreline reference in this study (Coyne et al., 1999; Fletcher et al., 2003). Many errors are introduced in the delineation of shorelines. For example, using aerial photographs taken at low tide will influence the location of the digitized shoreline, which in turn, influences the resulting erosion rate. We identify and quantify the various errors to assess the uncertainty of the position. The errors are squared and summed to get a total positional uncertainty. We assume the total uncertainty follows a Gaussian distribution, since the Central Limits Theorem states the sum of many sources of uncertainty tends toward a normal distribution (Draper and Smith, 1998). Identifying the probability distribution for each error process (e.g. tidal fluctuation, seasonal variance, etc.) provides us with the tools to calculate the individual error uncertainty.

We use two different images to generate our shoreline positions - topographic surveys (T-sheets) and aerial photographs. Only T-sheets that pass the National Map Accuracy Standards are used in this analysis (Fletcher et al., 2003). The surveyors of these T-sheets designated the Mean High Water Line (MHWL) as the shoreline position. We offset the MHWL in T-sheets to the beach toe.

We calculate the total positional uncertainty using the following equation: 


$$
E t p=\sqrt{E d^{2}+E p^{2}+E s^{2}+E r^{2}+E t d^{2}+E t s^{2}+E c^{2}}
$$

where $\mathrm{Ed}=$ digitizing error, $\mathrm{Ep}=$ pixel error, $\mathrm{Es}=$ seasonal error, $\mathrm{Er}=$ rectification error, $E t d=$ tidal fluctuation error, Ets $=$ error plotting on a T-sheet, and Ec $=$ error in converting from MHWL to beach toe on a T-sheet. Errors for T-sheets include Ets and Ec, and exclude Er and Etd. Aerial photographs do not include Ets and Ec.

An explanation of each measurement and the uncertainty contributing to the measurement is discussed below. We also examine the probability distribution of each error and the reasoning behind the method we used to calculate the error.

\section{Digitizing Error (Ed)}

Only one member of the Coastal Geology Group digitized the beach toe for all photographs and T-Sheets for any given portion of the Maui shoreline. This eliminated different beach toe interpretations from multiple users. The user visually determined the shorelines onscreen in PCI Geomatics using his knowledge of the area to interpret the beach toe.

If the analyst took repeated measurements (preferably $>100$ ) of the beach toe the resulting distribution would resemble a Gaussian distribution. Most measurements would concentrate around a central value (e.g., mean) with a decreasing number of measurements occurring away from that central value (Davis, 2002). Because three data runs is not enough to identify a distribution, we digitized one section of a beach in Maui 
(Little Beach) 50 times. Figure 2 is the histogram of the position of the beach toe on one transect, which resembles a Gaussian distribution.

The standard deviation of the differences between the three runs is the digitizing error. An updated table of digitizing errors from John Rooney's (Unpublished) explanation of uncertainties called EroRateUncert, is below.

\begin{tabular}{|l|l|l|l|l|l|}
\hline Year & 1997 & 1960 & 1949 & 1912 & 1900 \\
\hline Scale & 5,000 & 10,000 & 7,300 & 20,000 & 10,000 \\
\hline $\begin{array}{l}\text { Color/B\&W/T- } \\
\text { Sheet }\end{array}$ & Color & Color & B\&W & T-sheet & T-sheet \\
\hline Ed & $\mathbf{0 . 7 4 3 1}$ & $\mathbf{0 . 7 8 9 8}$ & $\mathbf{0 . 9 5 5 8}$ & $\mathbf{5 . 1 3 5 0}$ & $\mathbf{1 . 6 7 9 4}$ \\
\hline
\end{tabular}

Table 1: Digitizing Errors

According to Rooney's document, if one of the above digitizing errors has similar attributes (e.g. scale) to a year of a photo or T-sheet not mentioned above, that Ed (error) could be used for the unmentioned year. If no similar attributes exist, then the digitizing error should be calculated for that year. 


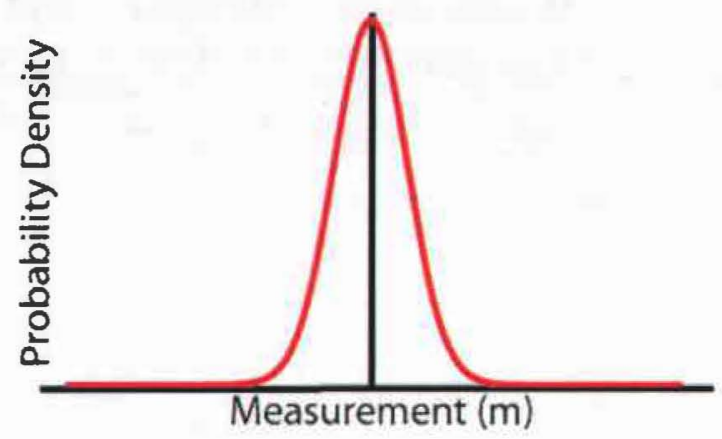

Figure 1: Gaussian (Normal) Distribution

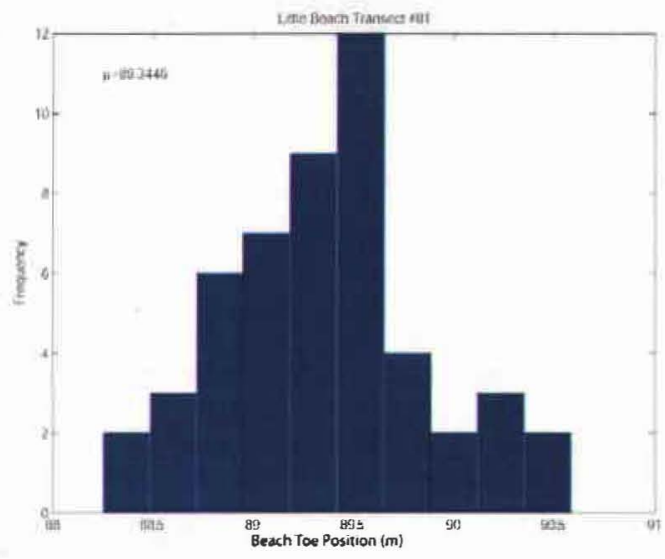

Figure 2: A histogram of 50 Beach Toe Interpretations.

\section{Pixel error (Ep)}

We attempt to measure the beach toe accurate to the pixel size of the image. The pixel size in the orthorectified images is $0.5 \mathrm{~m}$, which means anything within $0.5 \mathrm{~m}$ cannot be resolved.

Assuming we can identify the beach toe to the nearest two pixels, we know our maximum and minimum errors are $\quad \pm 0.5 \mathrm{~m}$. We can also assume that the true beach 
toe is found within $\pm 0.5 \mathrm{~m}$. This means we have an equal probability of identifying beach toe correctly within $\pm 0.5 \mathrm{~m}$. Therefore, the probability distribution is uniform.

To calculate the pixel error, we generate synthetic data $(>10000$ points) between -0.5 and +0.5 using the 'rand' function ('rand' generates data from a uniform distribution) in Matlab. If we plot the histogram of the data, it will look similar to Figure 3. We then take the standard deviation of the data to get a 1- $\sigma$ error, or Ep. Ep $=\mathbf{0 . 2 8 9} \mathbf{~ m}$.

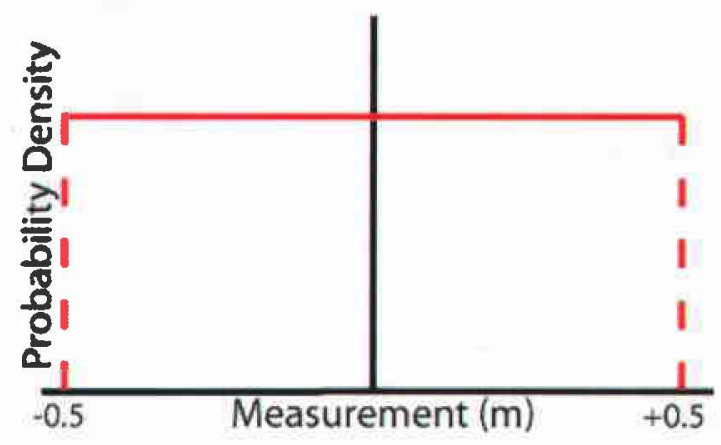

Figure 3: Uniform Distribution.

\section{Seasonal error (Es)}

Similar to tidal fluctuation, we did not select aerial photographs based on seasonal variation. It is important to note some beaches in Maui tend to accrete in summer and erode in winter, while other beaches tend to do the opposite. We chose to account for seasonal changes as an uncertainty in the shoreline position.

We model the seasonal uncertainty with a uniform distribution (see figure 3). Like tides, seasonal change occurs in a cyclical manner. The probability of the 
photograph depicting a summer shoreline is equal to the probability of the photograph describing a winter shoreline. Similar to tides, a "general" gaussian curve (see figure 4) is a more accurate approximation to the distribution due to seasonal anomalies; however, like tides, a uniform distribution is an easier and adequate substitution.

We digitized the shoreline position of two aerial photos - summer 1987 and winter 1988 - to identify the difference in position between the two seasons. We determine the mean absolute value $(\bar{x})$ and standard deviation absolute value $(\sigma)$ of the differences between the two seasonal shorelines. Analogous to the tide values, we conservatively take $\pm \bar{x}+2 \sigma$ as our minimum and maximum value for that specific study area. We use the rand function to generate data $(>10000$ points) between the minimum and maximum value and take the standard deviation of the data, which is the Es. Es will vary for each study area and has a range of $1.157-7.089 \mathrm{~m}$.

\section{Rectification Error (Er) [Aerial Photographs only]}

Aerial photographs are corrected, or rectified, to reduce displacements caused by lens distortion, earth curvature, refraction, camera tilt, and terrain relief (Welch and Jordan, 1996). Without the rectification of aerial photographs, these displacements would cause significant errors in identifying shoreline positions. We orthorectify our photos by applying a USGS (http://www.usgs.gov/) $10 \mathrm{~m}$ digital elevation model (DEM) and

ground control points (GCP) with map coordinates to the photo (Welch and Jordan, 1996). The Coastal Geology Group at the University of Hawaii amassed a database of 
GCPs in Maui using a differential GPS with sub-meter accuracy.

Because we have several independent errors within the rectification process, we can assume a Gaussian, or normal, distribution due to the Central Limits Theorem (Draper and Smith, 1998). The Central Limits Theorem states that if many sources contribute error, the resulting sum of the errors, regardless of the probability distribution of each error, tends toward a normal distribution.

Rectification error is produced in PCI Geomatics, Inc. (http://www.pcigeomatics.com/). The Root Mean Square (RMS) error is calculated, in pixels, for each year and includes both $\mathrm{X}$ and $\mathrm{Y}$ components. We calculated the total RMS error using Pythagoras theorem $-\sqrt{X^{2}+Y^{2}}$ - and then multiplied by $0.5 \mathrm{~m} / \mathrm{pixel}$ to get the error in meters. The rectification error (Er) will vary for each year at each geographic study area on Maui, but is not calculated for T-sheets. The range for Er is $0.100-6.050$ meters.

\section{Tidal fluctuation error (Etd) [Aerial Photographs only]}

We obtained aerial photographs without regard to tidal cycles, which results in inaccuracies on the digitized beach toes. Rather than correcting the measurement of shoreline positions due to tides, we calculate the possible fluctuations as an uncertainty that affects the true position of the shoreline.

We assume a uniform distribution (figure 3) for tidal fluctuation. Because the tides are cyclical fluctuating between low and high, we have an equal chance of taking a 
photograph of the shoreline at different stages of the tides. This means the probability of the photograph taken at high tide is identical to the probability of it taken at low tide. We can test this by recording the position of the beach toe at the same tide height multiple times. In reality, a "general" gaussian distribution (figure 4, (Tarantola, 1987)) is a better estimate of the probability distribution because spring and neap tides are higher and lower than normal tides; however, using a conservative application of a uniform distribution is sufficient in our case.

The horizontal movement of the beach toe on several beaches in Maui was monitored continuously over a spring tidal cycle. The displacement of the toe was found to be \pm 1.25 meters. To be conservative, we use \pm 2.5 , or twice the value, as our maximum and minimum values for a uniform distribution. The standard deviation of a uniform distribution that has max and min values equal to \pm 2.5 is $1.4 \mathrm{~m}$. This can be calculated numerically by using the rand function to generate values ( $>10000$ points) between \pm 2.5 . A histogram of the data looks similar to figure 1 with the maximum and minimum values equal to \pm 2.5 . The standard deviation of the data is the Etd. Etd $=1.4$ m.

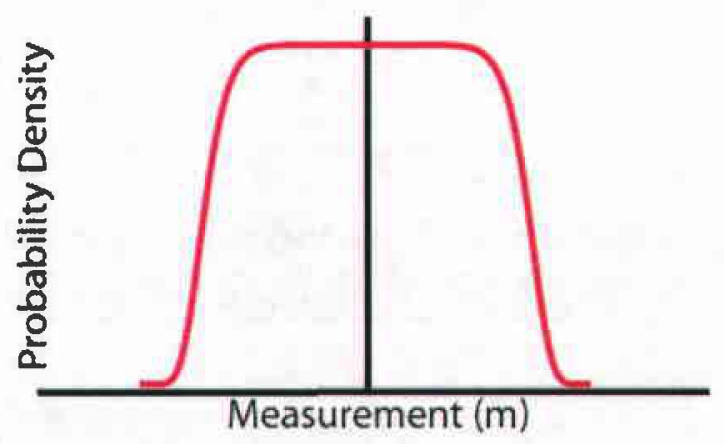

Figure 4: General Gaussian Distribution. This distribution is similar to a uniform distribution yet has tails similar to a gaussian curve. 


\section{Plotting T-sheet error (Ets) [T-sheets only]}

The plotting T-sheet error is based on Shalowitz (1964) thorough analysis of topographic surveys in Shore and Sea Boundaries. There are three major errors involved in the accuracy of these surveys: (1) measuring distances has an accuracy of 1 meter, (2) planetable position has an accuracy of 2-3 meters, and (3) delineation of the actual mean high water line is accurate to about 3-4 meters. Since most of the maps were made in the field, field notes usually do not exist. According to Shalowitz (1964), large errors do not exist in T-sheets because a continual check of the survey was done through triangulation.

The probability distribution for total plotting error is Gaussian (see Figure 1). If we took multiple measurements of the distances, the planetable position, and the delineation of the mean high water line, and plotted the measurements on a histogram, most measurements would reflect the mean value while some measurements would be slightly off. Similar to rectification error, we can cite the Central Limits Theorem that multiple sources of errors tend towards a gaussian distribution (Draper and Smith, 1998).

We calculate the total plotting error (Ets) for all T-sheets as a sum of squares of the three distinct errors mentioned above. We use $1 \mathrm{~m}$ for the error in distance, $3 \mathrm{~m}$ for the planetable accuracy and $4 \mathrm{~m}$ for the delineation of the mean high water line to compute Ets. $\mathbf{E t s}=\mathbf{5} \mathbf{~ m}$.

\section{Conversion error for T-sheets (Ec) [T-sheets only]}

As mentioned earlier, the surveyed shoreline on T-sheets is the Mean High Water Line (MHWL). Considering that generated shorelines are predominantly from aerial 
photographs, we convert the shorelines from T-sheets to the beach toe to minimize the resulting errors (Fletcher et al., 2003; Rooney et al., 2003). The Coastal Geology group collected five years of beach profile data on twenty-seven beaches in Maui that was used to offset the MHWL to the contemporaneous beach toe (Fletcher et al., 2003; Rooney et al., 2003). The offset is the median of the difference between the MHWL and the beach toe. For beaches without profiles, the offset from similar littoral areas was used to migrate the shoreline in question (Fletcher et al., 2003; Rooney et al., 2003).

We assume the probability distribution of this error is Gaussian (see Figure 1). Similar to the digitizing error, the range of data will surround a central value (Davis, 2002). We took values of the offset (median) - difference between MHWL and beach toe from multiple profiles in North Kaanapali ( a total of 63 points) and made a histogram (see figure 5). The histogram resembles a Gaussian distribution. By increasing the number of points, the resemblance will improve.

We subtract the median offset from the difference between MHWL and beach toe to identify the range of values around the median (Median Offset - (MHWL - Beach Toe)). The standard deviation of this difference is the conversion error $(\mathrm{Ec})$. Ec will vary for each profile area on Maui with a range of $1.967-7.507$ meters. 


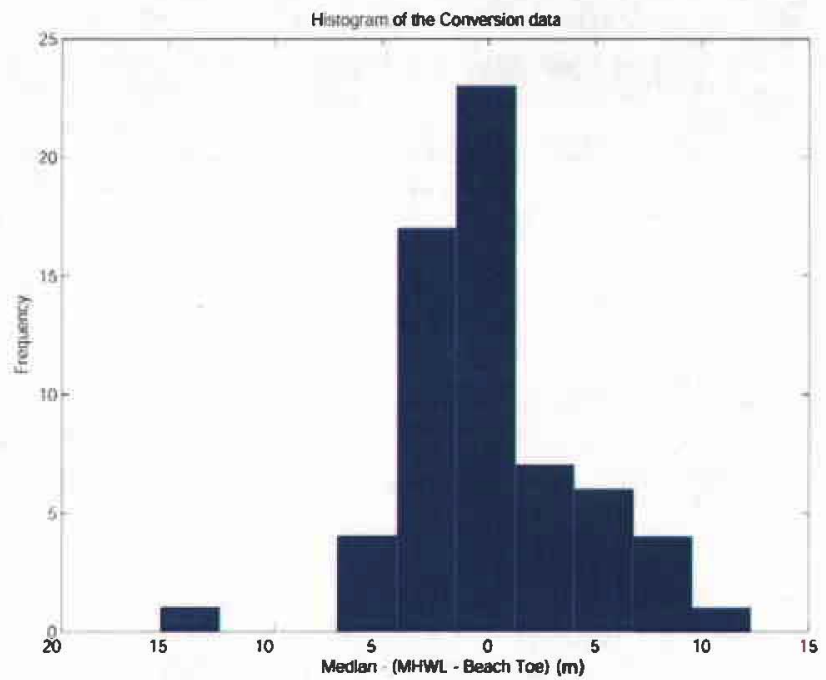

Figure 5: A histogram of the median offset for T-sheets subtracted by (MHWL-beach toe) from North Kaanapali. The histogram resembles a Gaussian distribution. 


\section{APPENDIX D: LAD EQUATIONS}

Following L. Neil Frazer's homework assignment in GG685 (Inverse Theory), the calculations for Least Absolute Deviation (LAD) are presented below. LAD assumes a two-sided Laplace distribution, which makes it more robust with respect to outliers than least squares.

The first step in identifying the LAD rate is to calculate the likelihood function for the slope $\left(b_{1}\right)$ and intercept $\left(b_{0}\right)$. The likelihood function, in this case, is the posterior density function (df) for both slope and intercept. The equation for the likelihood function $(\sigma)$ is:

$$
\sigma\left(b_{1}, b_{0}\right)=e^{\frac{-\sqrt{2}}{v} \sum_{i}\left|y_{i}-b_{0}-b_{1} x_{i}\right|}
$$

where $v$ is the estimator of the standard deviation, which is calculated by the equation:

$$
v=\frac{\sqrt{2}}{N-2} \sum_{i}\left|y_{i}-b_{0}-b_{1} x_{i}\right|
$$

where $\mathrm{N}$ is equal to the sample size. In the case of Weighted Least Absolute Deviation (WLAD), $v$ is simply the uncertainty at each $\mathrm{y}_{\mathrm{i}}$. A grid search is performed to calculate either the misfit function $\left(\sum_{i}\left|y_{i}-b_{0}-b_{1} x_{i}\right|\right)$ or the likelihood function $(\sigma)$ over a range of slopes and intercepts. The best fitting line is the one whose slope and intercept minimizes the misfit function or maximizes the likelihood function (the results of both the misfit and likelihood function will be the same). 
To compute the uncertainty of the slope (LAD rate), the marginal posterior $\mathrm{df}$ of the slope $\left(\sigma_{b_{1}}\left(b_{1}\right)\right)$ is calculated by integrating the joint pdf (in this case, the likelihood function) over the intercept. The following is the equation for the marginal posterior $\mathrm{df}$ of slope:

$$
\sigma_{b_{1}}\left(b_{1}\right)=\int_{-\infty}^{\infty} d b_{0} \sigma\left(b_{1}, b_{0}\right)
$$

Once the marginal posterior $\mathrm{df}$ is estimated, its cumulative distribution is calculated using the following equation:

$$
F\left(b_{1}\right)=\int_{-\infty}^{b_{1}} d b_{1}{ }^{\prime} \sigma\left(b_{1}^{\prime}\right)
$$

By interpolating $F\left(b_{l}\right)$, the slope uncertainty can be identified at the percentile of interest. 


\section{REFERENCES}

Coyne, M.A., Fletcher, C.H. and Richmond, B.M., 1999. Mapping Coastal Erosion Hazard Areas in Hawaii: Observation and Errors. Journal of Coastal Research, Special Issue 28: 171-184.

Crowell, M., Douglas, B.C. and Leatherman, S.P., 1997. On Forecasting Future U.S. Shoreline Positions: A Test of Algorithms. Journal of Coastal Research, 13(4): 1245-1255.

Crowell, M., Honeycutt, M. and Hatheway, D., 1999. Coastal Erosion Hazards Study: Phase One Mapping. Journal of Coastal Research, Special Issue 28: 10-20.

Davis, J.C., 2002. Statistics and Data Analysis in Geology. John Wiley \& Sons, New York, $638 \mathrm{pp}$.

Dean, R.G. and Malakar, S.B., 1999. Projected Flood Hazard Zones in Florida. Journal of Coastal Research, Special Issue 28: 85-94.

Dolan, R., Fenster, M.S. and Holme, S.J., 1991. Temporal Analysis of Shoreline Recession and Accretion. Journal of Coastal Research, 7(3): 723-744.

Douglas, B.C., Crowell, M. and Leatherman, S.P., 1998. Considerations for Shoreline Position Prediction. Journal of Coastal Research, 14(3): 1025-1033.

Draper, N.R. and Smith, H., 1998. Applied Regression Analysis. John Wiley \& Sons, Inc., New York.

Eversole, D., 2002. Large-Scale Beach Change: Kaanapali, Hawaii. M.S. Thesis, University of Hawaii, Manoa, $63 \mathrm{pp}$.

Eversole, D. and Fletcher, C.H., 2003. Longshore Sediment Transport Rates on a ReefFronted Beach: Field Data and Empirical Models Kaanapali Beach, Hawaii. Journal of Coastal Research, 19(3): 649-663.

Fenster, M. and Dolan, R., 1994. Large-scale reversals in shoreline trends along the U.S. mid-Atlantic coast. Geology, 22: 543-546.

Fenster, M.S., Dolan, R. and Elder, J.F., 1993. A New Method for Predicting Shoreline Positions from Historical Data. Journal of Coastal Research, 9(1): 147-171.

Fenster, M.S., Dolan, R. and Morton, R.A., 2001. Coastal Storms and Shoreline Change: Signal or Noise? Journal of Coastal Research, 17(3): 714-720.

Fletcher, C.H., Grossman, E.E., Richmond, B.M. and Gibbs, A., 2002. Atlas of Natural Hazards in the Hawaiian Costal Zone. U.S. Geologic Survey, pp. 182.

Fletcher, C.H., Mullane, R.A. and Richmond, B.M., 1997. Beach Loss Along Armored Shorelines on Oahu, Hawaiian Islands. Journal of Coastal Research, 13(1): 209. 215.

Fletcher, C.H., Rooney, J.J.B., Barbee, M., Lim, S.-C. and Richmond, B.M., 2003. Mapping Shoreline Change Using Digital Orthophotogrammetry on Maui, Hawaii. Journal of Coastal Research, Special Issue 38: 106-124.

Foster, E.R. and Savage, R.J., 1989. Methods of Historical Shoreline Analysis, Coastal Zone '89. American Society of Civil Engineers, New York, pp. 4434-4448.

Galgano, F.A. and Douglas, B.C., 2000. Shoreline Position Prediction: Methods and Errors. Environmental Geosciences, 7(1): 23-31.

Galgano, F.A., Douglas, B.C. and Leatherman, S.P., 1998. Trends and Variability of Shoreline Position. Journal of Coastal Research, Special Issue 26: 282-291. 
Graybill, F.A. and Iyer, H.K., 1994. Regression Analysis: Concepts and Applications. Duxbury Press, Belmont, CA, 701 pp.

Honeycutt, M.G., Crowell, M. and Douglas, B.C., 2001. Shoreline-Position Forecasting: Impact of Storms, Rate-Calculation Methodologies, and Temporal Scales. Journal of Coastal Research, 17(3): 721-730.

Kleinbaum, D.G., Kupper, L.L., Muller, K.E. and Nizam, A., 1998. Applied Regression Analysis and Other Multivariable Methods. Duxbury Press, Pacific Grove, CA, $798 \mathrm{pp}$.

Makai Ocean Engineering and Sea Engineering, 1991. Aerial Photograph Analysis of Coastal Erosion on the Islands of Kauai, Molokai, Lanai, Maui and Hawaii.

Morton, R.A., 1991. Accurate Shoreline Mapping: Past, Present, and Future, Coastal Sediments '91, pp. 997-1010.

Norcross-Nu'u, Z.M. and Abbott, T., 2005. Adoption of Erosion Rate-Based Setbacks in Maui, Hawaii: Observations and Lessons Learned, Solutions to Coastal Disasters Conference, Charleston, S.C.

Ocean Studies Board, 1999. Science for decision-making, Commission on Geosciences, Environment and Resources. National Research Council, National Academy Press, Washington D.C., pp. 113.

Rissanen, J., 1989. Stochastic Complexity in Statistical Inquiry. World Scientific, Singapore, $178 \mathrm{pp}$.

Rooney, J.J.B., 2002. A Century of Shoreline Change Along the Kihei Coast of Maui, Hawaii. Ph.D. dissertation Thesis, University of Hawaii, Manoa, 174 pp.

Rooney, J.J.B., Unpublished. EroRateUncert, Microsoft Word Document.

Rooney, J.J.B. and Fletcher, C.H., 2000. A High Resolution, Digital, Aerial Photogrammetric Analysis of Historical Shoreline Change and Net Sediment Transport Along the Kihei Coast of Maui, Hawaii, Thirteenth Annual National Conference on Beach Preservation Technology, Melbourne, FL.

Rooney, J.J.B. and Fletcher, C.H., in press. Shoreline Change and Pacific Climatic Oscillations in Kihei, Maui, Hawaii. Journal of Coastal Research.

Rooney, J.J.B., Fletcher, C.H., Barbee, M., Eversole, D., Lim, S.-C., Richmond, B.M. and Gibbs, A., 2003. Dynamics of Sandy Shorelines in Maui, Hawaii: Consequences and Causes, Coastal Sediments '03 Proceedings, Clearwater Beach, Florida.

Rousseeuw, P.J. and Leroy, A.M., 1987. Robust Regression and Outlier Detection. John Wiley \& Sons, Inc., New York, 329 pp.

Seber, G.A.F. and Lee, A.J., 2003. Linear Regression Analysis. Wiley Series in Probability and Statistics. John Wiley \& Sons, Inc., Hoboken, NJ, 557 pp.

Shalowitz, A.L., 1964. Shore and Sea Boundaries, 2. Publication 10-1, U.S. Department of Commerce, Washington D.C.

Siegel, S., 1956. Nonparametric Statistics For The Behavioral Sciences. McGraw-Hill Book Company, Inc., New York, 312 pp.

Tarantola, A., 1987. Inverse Problem Theory Methods for Data Fitting and Model Parameter Estimation. Elsevier, New York, 613 pp.

Thieler, E.R., Rodriguez, R.W. and Carlo, M., 1995. Beach Erosion and Coastal Development at Rincon, Puerto Rico. Shore and Beach, 63(4): 18-28. 
Welch, R. and Jordan, T.R., 1996. Using Scanned Air Photographs. In: S.M.a.S.L. Baros (Editor), Raster Imagery in Geographic Information Systems. Onward Press, pp. 55-69.

Zhang, K., Douglas, B. and Leatherman, S., 2002. Do Storms Cause Long-Term Beach Erosion along the U.S. East Barrier Coast? Journal of Geology, 110(4). 